
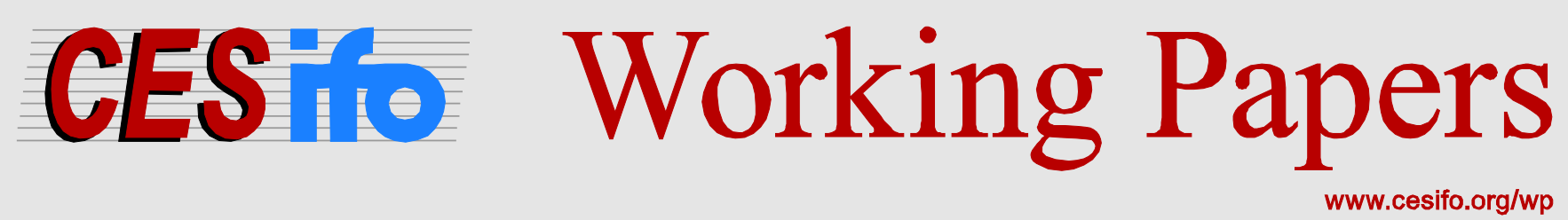

\title{
Policy Risk and the Business Cycle
}

\author{
Benjamin Born \\ Johannes Pfeifer
}

CESIFO WORKING PAPER NO. 4336

CATEgory 6: Fiscal Policy, Macroeconomics and Growth

JULY 2013

An electronic version of the paper may be downloaded

- from the SSRN website:

- from the RePEc website:

- from the CESifo website:

wWw.SSRN.com

www.RePEc.org

www.CESifo-group.org/wp

\section{CESifo}




\title{
Policy Risk and the Business Cycle
}

\begin{abstract}
The argument that policy risk, i.e., uncertainty about monetary and fiscal policy, has been holding back the economic recovery in the U.S. during the Great Recession has a large popular appeal. We analyze the role of policy risk in explaining business cycle fluctuations by using an estimated New Keynesian model featuring policy risk as well as uncertainty about technology. We directly measure uncertainty from aggregate time series and find considerable evidence of time-varying policy risk in the data. However, the "pure uncertainty"-effect of policy risk is unlikely to play a major role in business cycle fluctuations. In the estimated model, output effects are relatively small because the aggregate policy risk shocks are i) too small and ii) not sufficiently amplified.
\end{abstract}

JEL-Code: E320, E630, C110.

Keywords: policy risk, uncertainty, aggregate fluctuations, particle filter, nominal rigidities.

Benjamin Born

University of Mannheim

L7, 3-5

68131 Mannheim

Germany

born@uni-mannheim.de
Johannes Pfeifer

University of Tuebingen

Mohlstraße 36

72074 Tuebingen

Germany

johannes.pfeifer@uni-tuebingen.de

This version: July 11, 2013

First Version: December 2010

We would like to thank Ricardo Reis, Giorgio Primiceri, an anonymous referee, Klaus Adam, Christian Bayer, Kai Christoffel, Zeno Enders, Michael Evers, Patrick Hürtgen, Christian Matthes, Alexandra Peter, Christian Pigorsch, and Kevin Sheedy for helpful discussions. Special thanks go to Gernot Müller. We greatly benefited from comments by seminar audiences in Bonn, Mannheim, Munich, Tuebingen, the European Central Bank, and the Bank of England, as well as participants at the 2012 Becker-Friedman Conference, the EEA/ESEM 2012, the Royal Economic Society Annual Conference 2012, the Spring Meeting of Young Economists 2011, the IWH/CIREQ Macroeconometric Workshop 2011, and the 43rd Konstanz Seminar on Monetary Theory and Policy. All remaining errors are our own. 


\section{Introduction}

The supposedly negative influence of "policy risk", i.e., uncertainty about fiscal and monetary policy, has become a recurring theme in the political discourse. The popular argument espoused in speeches and newspaper articles by politicians and economists alike is that the uncertainty surrounding future policy stuns economic activity by inducing a "wait-and-see" approach. ${ }^{1}$ In the following, we think of uncertainty as the dispersion of the economic shock distribution, i.e., a mean-preserving spread. Rational consumers and firms react to the fact that future shocks will be drawn from a wider distribution. This reaction is distinct from the ex-post effect of higher volatility resulting from on average more extreme shock realizations. The goal of the present study is to isolate the first effect and answer the question: Are uncertainty shocks to policy variables quantitatively important?

Scientific evidence on the aggregate effects of uncertainty is still inconclusive. Empirical studies using different proxies and identification schemes to uncover the effects of uncertainty have produced a variety of results. One group of studies reports a large impact of uncertainty about productivity on aggregate variables like GDP and employment (Alexopoulos and Cohen, 2009; Bloom, 2009; Bloom et al., 2012). A one-standard deviation shock to uncertainty in these studies typically leads to a $1 \%-2 \%$ drop in GDP, followed by a recovery with a considerable overshooting. In contrast, a second group of studies reports little to no impact at all (Bachmann and Bayer, forthcoming; Bachmann et al., 2013; Bekaert et al., 2010; Chugh, 2011). In the theoretical literature, while most studies have emphasized the contractionary effects of uncertainty on economic activity, it is generally acknowledged that there are different effects working in opposite directions, thereby making the overall effect ambiguous. For example, an increase in uncertainty may depress investment due to the "wait-and-see" approach. But at the same time economic agents may want to self-insure by working more to build up a buffer capital stock, which ceteris paribus leads to an increase in investment.

We answer the question of whether policy risk shocks are quantitatively important in an estimated DSGE-model. We focus on aggregate uncertainty as it has been shown to have potentially important output effects (Fernández-Villaverde et al., 2011). We add to the previous literature in the following ways. First, together with the independently conducted contemporaneous work by Fernández-Villaverde et al. (2012), we are the first to study the effect of policy risk on business cycles. Second, we directly measure aggregate uncertainty from the respective time series without the need to resort to proxies. Third, we jointly consider

\footnotetext{
${ }^{1}$ See, e.g., The Wall Street Journal, October 29th, 2009: "For these small businesses, and many others [...], there's an additional dark cloud: uncertainty created by Washington's bid to reorganize a wide swath of the U.S. economy." (Fields, 2009). For other proponents of this view, see Boehner (2010); Cantor (2010); for dissenting opinions, see, e.g., Klein (2010).
} 
level shocks and uncertainty shocks. Regarding uncertainty shocks, we focus on policy risk, i.e., uncertainty about future tax liabilities, government spending, and monetary policy, to test the hypothesis that policy risk may be an important factor in explaining the prolonged Great Recession. We also include uncertainty with respect to total factor productivity (TFP) and investment-specific technology in order to have a benchmark against which we can judge our findings. Fourth, we integrate these processes into a medium-scale New Keynesian DSGE-model of the type typically used for policy analysis (see, e.g., Christiano et al., 2005; Smets and Wouters, 2007) and solve this model using third-order perturbation methods. We then estimate the model using the Simulated Method of Moments. This approach allows us to control for the effects of level shocks to TFP, investment-specific technology, government spending, monetary policy, and taxes when estimating the importance of policy risk.

We find that the role of policy risk in explaining business cycles is overstated. Although the output effects of policy risk are four times larger than the effects of TFP uncertainty, even a two-standard deviation shock to policy risk decreases output by a mere $0.045 \%$. The are two reasons for this: First, uncertainty shocks are relatively small and, second, the propagation is too weak to result in a significant amplification of aggregate uncertainty shocks.

The most important mechanism driving the response to policy risk in our model is the price setting mechanism of firms constrained by sticky prices. An increase in uncertainty induces households to work more, which lowers wages and firms' marginal costs. As prices are sticky this translates into higher markups. In an economy that is fundamentally demand-driven in the short run, this increase in markups is contractionary. This economic mechanism has been documented in great detail in Basu and Bundick (2012). At the same time, there is an "inverse Hartman-Abel effect" because sticky prices make the firms' marginal profit function convex, as firms have to satisfy demand given their preset price. Being stuck with a too low relative price means selling more goods at a lower profit or even a loss, while too high a price reduces the quantity, but at the same time increases per-unit profits. Thus, in response to increased uncertainty firms will raise markups in order to self-insure against being stuck with too low a price, leading to a decrease in output and an increase in inflation.

After the first working paper version of this paper, we have become aware of independently conducted work by Fernández-Villaverde et al. (2012), studying a similar issue in a calibrated model. Due to the common antecedents in our contemporaneous work (Christiano et al., 2005; Fernández-Villaverde et al., 2011; Leeper et al., 2010; Smets and Wouters, 2007), the methodology and many modeling choices are similar. Differences lie in the set of shocks considered and in the details of the model specification and parametrization. In terms of results, the effects of policy uncertainty in their study are qualitatively similar to ours but somewhat larger, stemming mostly from a larger steady state demand elasticity. Also 
closely related to our work is the paper by Baker et al. (2013), who construct a measure of policy uncertainty from newspaper articles, legislative texts, and surveys. Using a structural VAR identification, they argue that policy uncertainty was a main factor driving the Great Recession, but find it hard to establish causality. Our study can be seen as a quantitative thought experiment that takes all uncertainty observed in the data as a causal driving force and analyzes its implications through the lens of a monetary DSGE model.

The outline of the paper is as follows: Section 2 discusses the theoretical transmission channels of uncertainty. Section 3, explains the model. In Section 4, we measure uncertainty directly from aggregate time series. Section 5 estimates the model and Section 6 studies the effects of policy risk in the estimated model. Section 7 concludes.

\section{Uncertainty: Potential Transmission Channels}

Three different mechanisms through which aggregate uncertainty may affect economic activity have been identified in the microeconomic literature: Hartman-Abel effects, real option effects, and precautionary savings. While these categories are helpful in shaping our thinking about the effects of uncertainty, they are partial equilibrium effects. In general equilibrium, each of these effects necessarily induces equilibrating price and quantity changes that may significantly dampen the aggregate effects. In a partial equilibrium model, uncertainty may have ceteris paribus largely contractionary effects on investment and output (e.g., Bloom, 2009). However, in general equilibrium wages and interest rates may adjust, thereby significantly reducing the resulting net effect (Bachmann and Bayer, forthcoming). ${ }^{2}$

The first category are the so called Hartman-Abel effects (Abel, 1983; Hartman, 1972). Under certain conditions, it follows from the firm's FOC that the expected marginal revenue product of capital is convex in output prices and TFP. ${ }^{3}$ Hence, due to Jensen's Inequality, larger uncertainty about these variables increases the demand for capital and thus investment. In our model, while capital is predetermined, both the utilization of capital and labor input can be adjusted, opening up the possibility of expansionary Hartman-Abel effects.

However, given sticky prices, there may exist an "inverse Hartman-Abel effect". As prices cannot be fully adjusted and all demand has to be satisfied, the marginal profit curve becomes

\footnotetext{
${ }^{2}$ While the main result of Bachmann and Bayer (forthcoming) is that the overall volatility of uncertainty shocks is too small to matter for unconditional moments, they also report that when shutting off the general equilibrium effects in their model, the importance of uncertainty shocks increases by about $50 \%$.

${ }^{3}$ The reason is that labor can flexibly react to shocks and hence the marginal revenue product reacts stronger than one for one to the movement in the respective variable. To see this, assume a fixed stock of capital and a rising output price. There is a direct positive effect of this price increase on profits via quantity times price change. Additionally, there is a positive indirect effect through the increase in optimal output that is achieved by increasing labor.
} 
convex in relative prices. Setting prices too low results in having to sell more goods at a lower markup/higher loss, while setting the price too high results in selling a lower quantity of goods, but at a higher profit per unit. Thus, firms will choose higher prices and thus higher markups over marginal costs if uncertainty increases, thereby dampening demand and in general equilibrium potentially output. ${ }^{4}$

Second, there may be real option effects at work (Bernanke, 1983), e.g., through investment being (partially) irreversible and/or only partially expandable. For example, if the resale (purchase) price of capital in the future differs from the current acquisition price, a firm installing capital that it may sell later, effectively acquires a put option. Moreover, investment today destroys a call option, namely the opportunity to buy capital later at a possibly lower price. Hence, in the investment decision these option values have to be taken into account (Abel et al., 1996). Higher uncertainty decreases investment as the call option to purchase the capital later, which is "killed" by investing today, becomes more valuable. However, in the presence of partial reversibility, the value of the put option that is obtained by investing today increases with higher uncertainty. Hence, the total effect of uncertainty on investment in such a framework is generally ambiguous.

In our model, several features give rise to option effects. First, capital is predetermined for one period. Second, the relative price of investment and consumption is stochastic, thereby giving rise to potentially costly irreversibility and expandability. Third, through the presence of depreciation allowances, investment generates a tax shield at historical costs of investment so that investment today effectively "kills" the option to purchase this tax shield later. Fourth, the interest rate in our model is stochastic, giving rise to additional countervailing option effects as discussed in Ingersoll and Ross (1992).

The third effect is the precautionary savings motive, defined as the "additional saving that results from the knowledge that the future is uncertain" (Carroll and Kimball, 2008). Faced with higher uncertainty, agents may both consume less and work more in order to self-insure against future shocks, i.e., they build up a buffer stock. As the preferences of the agents in our model feature prudence, uncertainty should increase precautionary savings in our model.

Apart from these microeconomic effects, Basu and Bundick (2012) recently identified a distinctively macroeconomic effect that is prominently at play in our model. They show that uncertainty shocks in standard closed economy RBC models always generate the counterintuitive results that uncertainty is expansionary. The precautionary motive of households leads to an increase in labor supply. Given that capital is predetermined and uncertainty shocks do not alter TFP, output will go up. This mechanism changes in a model with monopolistic competition and sticky prices and/or wages: increased uncertainty leads to increases in firms' and

\footnotetext{
${ }^{4}$ See Pfeifer et al. (2012) for an example of this mechanism at work in an open economy context.
} 
Table 1: Overview: potential transmission mechanism

\begin{tabular}{|c|c|c|c|c|c|c|c|}
\hline & Hartman-Abel & Inv. Hartman- & Rea & opti & n effects & Precaut. & Basu-Bundick \\
\hline & effects & Abel effect & Call & Put & Int. rate & savings & effect \\
\hline Invest. & + & - & - & + & $+/-$ & + & - \\
\hline Cons. & + & - & $?$ & $?$ & $?$ & - & - \\
\hline
\end{tabular}

Notes: + indicates a positive effect of uncertainty, - a negative effect, and +/ - an ambiguous effect on the respective variable. ? denotes that the respective effect makes no prediction for this variable due to its partial equilibrium nature.

unions' markups. Because in sticky price models output is fundamentally demand-determined, the increased wedge introduced by time-varying markups in response to uncertainty shocks reduces GDP instead of raising it. However, for this mechanism to be operative, prices and/or wages need to be sufficiently sticky. In the limit, New Keynesian models converge to the RBC model and will exhibit an expansion in response to uncertainty shocks.

In the end, due to these five effects, summarized in Table 1, acting on different variables and potentially working in opposite directions as well as the presence of general equilibrium effects and nominal rigidities, only a rigorous quantitative evaluation can answer the question of what the net effect of uncertainty on aggregate activity is. We pursue this question by estimating a structural model featuring time-varying volatility, which we present in the next section.

\section{A DSGE-model with Policy Risk}

We use a standard quantitative New Keynesian business cycle model (e.g., Smets and Wouters, 2007). The model economy is populated by a large representative family, a continuum of unions $j \in[0,1]$ selling differentiated labor services to intermediate firms, a continuum of intermediate firms producing differentiated intermediate goods using bundled labor services and capital, and a final good firm bundling intermediate goods to a final good. In addition, the model features a government sector that finances government spending with distortionary taxation and transfers, and a monetary authority, which sets the nominal interest rate according to an interest rate rule.

\subsection{Household Sector}

The economy is populated by a large representative family with a continuum of members, each consuming the same amount and working the same number of hours. Preferences 
are defined over per capita consumption $C_{t}$ and per capita labor effort $L_{t}$. Following the framework in Schmitt-Grohé and Uribe (2006), labor is supplied to a continuum of unions $j \in[0,1]$, which are monopolistically competitive and supply differentiated labor services $L_{t}(j)$. Household members supply their labor uniformly to all unions. Hence, total labor supply of the representative family is given by the integral over all labor markets $j$, i.e., $L_{t}=\int_{0}^{1} L_{t}(j) d j$. The labor market structure will be discussed in more detail below. We assume the preference specification of Jaimovich and Rebelo (2009), but allow for habits in consumption:

$$
U=E_{0} \sum_{t=0}^{\infty} \beta^{t} \xi_{t}^{\text {pref }} \frac{1}{1-\sigma_{c}}\left\{\left(C_{t}-\phi_{c} C_{t-1}-\gamma \frac{L_{t}^{1+\sigma_{l}}}{1+\sigma_{l}} S_{t}\right)^{1-\sigma_{c}}-1\right\}
$$

where $\phi_{c} \in[0,1]$ measures the degree of internal habit persistence, $\sigma_{c} \geq 0$ governs the intertemporal elasticity of substitution, $\sigma_{l} \geq 0$ is related to the Frisch elasticity of labor supply, and $\gamma \geq 0$ measures the relative disutility of labor effort. The term

$$
S_{t}=\left(C_{t}-\phi_{c} C_{t-1}\right)^{\sigma_{G}} S_{t-1}^{1-\sigma_{G}}
$$

makes the preferences non-separable in both consumption and work effort, where $\sigma_{G} \in[0,1]$ parameterizes the strength of the wealth effect on the labor supply. When $\sigma_{G}=1$, the preference specification is equal to the one discussed in King et al. (1988), while with $\sigma_{G}=0$ the preference specification of Greenwood et al. (1988) with no wealth effect on the labor supply is obtained. We assume the preference shock $\xi_{t}^{\text {pref }}$ to follow an $A R(1)$-process in logs:

$$
\log \xi_{t}^{\text {pref }}=\rho^{\text {pref }} \log \xi_{t-1}^{\text {pref }}+\varepsilon_{t}^{\text {pref }}, \varepsilon_{t}^{\text {pref }} \stackrel{\text { iid }}{\sim} \mathcal{N}\left(0,\left(\sigma^{\text {pref }}\right)^{2}\right)
$$

Due to the impossibility of identifying the preference shocks directly from the data, we estimate this process in the second stage of our estimation approach using the simulated method of moments. Following the finding in Justiniano and Primiceri (2008) that there is little evidence for time-varying volatility in preference shocks, we assume a constant standard deviation $\sigma^{\text {pref }}$.

The household faces the budget constraint

$$
\begin{aligned}
C_{t}+z_{t}^{I} I_{t}+\frac{B_{t}}{P_{t}}= & \left(1-\tau_{t}^{n}\right) \int_{0}^{1} W_{t}(j) L_{t}(j) d j+\left(1-\tau_{t}^{k}\right) r_{t}^{k} u_{t} K_{t-1} \\
& +\left(1-\tau_{t}^{k}\right)\left(R_{t-1}-1\right) \frac{B_{t-1}}{P_{t}}+\frac{B_{t-1}}{P_{t}}+\Phi_{t}+T_{t}+\left(1-\tau_{t}^{k}\right) \Xi_{t},
\end{aligned}
$$

where the household earns income from supplying differentiated labor services $L_{t}(j)$ at the real wage $W_{t}(j)$ to union $j$, and from renting out capital services $u_{t} K_{t-1}$ at the rental rate 
$r_{t}^{k}{ }^{5}$ In addition, it receives lump sum transfers $T_{t}$ from the government and profits $\Xi_{t}$ from owning the firms in the economy. All forms of income are taxed at their respective tax rates $\tau_{t}^{n}$ and $\tau_{t}^{k}$. The term $\left(1-\tau_{t}^{k}\right)\left(R_{t-1}-1\right) \frac{B_{t-1}}{P_{t}}+\frac{B_{t-1}}{P_{t}}$ is the after-tax return on savings in government bonds, where the net returns are taxed at the capital tax rate. The household spends its income on consumption $C_{t}$ and investment $z_{t}^{I} I_{t}$, where $I_{t}$ is gross investment and $z_{t}^{I}$ denotes a shock to the relative price of investment in terms of the consumption good. This price is equal to the technical rate of transformation between investment and consumption goods. Due to the presence of a temporary shock, it is exogenous and stochastic. Changes in $z_{t}^{I}$ do not affect the productivity of already installed capital, but do affect newly installed capital and become embodied in it. We assume the shock to follow an AR(2)-process ${ }^{6}$

$$
\log z_{t}^{I}=\rho_{1}^{z I} \log z_{t-1}^{I}+\rho_{2}^{z I} \log z_{t-2}^{I}+e^{\sigma_{t}^{z I}} \nu_{t}^{z I} \nu_{t}^{z I} \stackrel{i i d}{\sim} \mathcal{N}(0,1)
$$

where $\sigma_{t}^{z I}$ allows for time-varying volatility and is discussed in detail in Section 4. Apart from the fact that this form of investment-specific technology may be an important source of economic fluctuations (Greenwood et al., 1997, 2000), a stochastic relative price of investment introduces costly reversibility and expandability of investment into the model as the future purchase/resale price is stochastic.

The term $\Phi_{t}$ captures depreciation allowances, i.e., the fact that the replacement of depreciated capital can be deducted from the tax base, which is an important feature of the U.S. tax code. We assume depreciation allowances of the form

$$
\Phi_{t}=\tau_{t}^{k} \sum_{s=1}^{\infty} \delta_{\tau}\left(1-\delta_{\tau}\right)^{s-1} z_{t-s}^{I} I_{t-s},
$$

which works as follows: $z_{t-s}^{I} I_{t-s}$ is the historical purchase price of capital investment. We assume a geometric depreciation schedule with depreciation rate $\delta_{\tau} \cdot{ }^{7}$ Thus, $\left(1-\delta_{\tau}\right)^{s-1} z_{t-s}^{I} I_{t-s}$ is the non-depreciated book value of the capital bought $s$ periods before, while $\delta_{\tau}(1-$ $\left.\delta_{\tau}\right)^{s-1} z_{t-s}^{I} I_{t-s}$ is the depreciation of this remaining book value of capital at time $t$. The infinite sum then sums up the current period's depreciation of the non-depreciated book values of all previous capital investments. Finally, this amount of depreciation for tax purposes lowers the tax base by the corresponding amount and thus decreases the tax liabilities by the capital tax rate $\tau_{t}^{k}$ times the tax base. By providing new investment with a tax shield, depreciation allowances may be important in capturing the dynamics of investment following

\footnotetext{
${ }^{5}$ Throughout the paper, we use the stock at the end of period timing convention.

${ }^{6}$ The lag lengths for the individual exogenous driving processes are chosen to provide a good empirical fit. Details are provided in Section 4.

${ }^{7}$ Following Auerbach (1989), we allow the depreciation rate for tax purposes to differ from the physical rate.
} 
shocks (Christiano et al., 2011a; Yang, 2005). Through this tax shield at historical investment prices, combined with a stochastic relative price of investment $z^{I}$, depreciation allowances also contribute to costly reversibility and expandability of investment.

The household owns the capital stock $K_{t}$, whose law of motion is given by

$$
K_{t}=\left[1-\left(\delta_{0}+\delta_{1}\left(u_{t}-1\right)+\frac{\delta_{2}}{2}\left(u_{t}-1\right)^{2}\right)\right] K_{t-1}+I_{t}-\frac{\kappa}{2}\left(\frac{I_{t}}{K_{t-1}}-\delta_{0}\right)^{2} K_{t-1} .
$$

Household members do not simply rent out capital, but capital services $u_{t} K_{t-1}$, where $u_{t}$ denotes the capital utilization, i.e., the intensity with which the existing capital stock is used. Without loss of generality, capital utilization in steady state is normalized to 1. Using capital with an intensity higher than normal incurs costs to the household in the form of a higher depreciation $\delta\left(u_{t}\right)=\delta_{0}+\delta_{1}\left(u_{t}-1\right)+\delta_{2} / 2\left(u_{t}-1\right)^{2}$, which, assuming $\delta_{0}, \delta_{1}, \delta_{2}>0$, is an increasing and convex function of capital utilization. The last term in equation (7) captures capital adjustment costs at the household level of the form introduced by Hayashi (1982), where $\kappa \geq 0$ is a parameter governing the curvature of the cost function. This functional form implies that capital adjustment costs are minimized and equal to 0 in steady state. We choose this type of adjustment costs for two reasons. First, while this functional form clearly is unable to explain some micro-level phenomena like lumpy investment, it has nevertheless been shown to provide a good fit of firm level investment data and performs better than the Christiano et al. (2005)-formulation with quadratic adjustment costs in investment changes (Eberly et al., 2008). Second, with the flow specification of Christiano et al. (2005), Tobin's marginal $q$ would be independent of the capital stock, which would essentially shut off intertemporal linkages and thereby the option effects (Wu, 2009).

Thus, the household maximizes its utility (1) by choosing $C_{t}, B_{t}, u_{t}, K_{t}, I_{t}, S_{t}, L_{t}$, subject to the constraints (2) - (7) and the resource constraint for aggregate labor.

\subsection{Labor Market}

The household supplies labor $L_{t}(j)$ equally to a continuum of unions $j, j \in[0,1]$. This labor market structure allows to introduce differentiated labor services and staggered wage setting without letting idiosyncratic wage risk affect the individual household members, which would make aggregation intractable. Monopolistically competitive unions supply differentiated labor $L_{t}(j)$ to intermediate firms at wage $W_{t}(j)$. Every period, each union may re-optimize its wage with probability $\left(1-\theta_{w}\right), 0<\theta_{w}<1$. If a union $j$ cannot re-optimize, its nominal wage is indexed to the price level according to $W_{t}(j) P_{t}=\prod_{t-1}^{\chi_{w}} W_{t-1}(j) P_{t-1}$, where $\chi_{w} \in[0,1]$ measures the degree of indexing. Hence, when the union has not been able to re-optimize for $\tau$ periods, its real wage $\tau$ periods ahead, $W_{t+\tau}(j)$, is given by $W_{t+\tau}^{o p t}(j)$ if the union is able to 
re-optimize in $t+\tau$ and $\prod_{s=1}^{\tau}\left(\Pi_{t+s-1}^{\chi_{w}} / \Pi_{t+s}\right) W_{t}(j)$ otherwise. Household members supply the amount of labor services that is demanded at the current wage. The objective of each union able to reset its wage is to choose the real wage that maximizes the expected utility of its members, given the demand for its labor services $L_{t}(j)=\left(W_{t}(j) / W_{t}\right)^{-\eta_{w}} L_{t}^{\text {comp }}$, where $L_{t}^{\text {comp }}$ is the aggregate demand for composite labor services and $\eta_{w}$ is the substitution elasticity, the respective resource constraint $L_{t}=L_{t}^{c o m p} \int_{0}^{1}\left(W_{t}(j) / W_{t}\right)^{-\eta_{w}} d j$, and the aggregate wage level $W_{t}=\left(\int_{0}^{1} W_{t}(j)^{1-\eta_{w}} d j\right)^{\frac{1}{1-\eta_{w}}}$.

\subsection{Firm Side}

There is a continuum of monopolistically competitive intermediate goods firms $i, i \in[0,1]$, which produce differentiated intermediate goods $Y_{i t}$ using capital services $K_{i t}^{s e r v}=u_{i t} K_{i t-1}$ and a composite labor bundle $L_{i t}^{c o m p}$ according to a Cobb-Douglas production function with capital share $\alpha$

$$
Y_{i t}=z_{t}\left(K_{i t}^{\text {serv }}\right)^{\alpha}\left(L_{i t}^{\text {comp }}\right)^{1-\alpha}-\xi_{t}^{\text {fixcost }} \phi, \quad \text { if } z_{t}\left(K_{i t}^{\text {serv }}\right)^{\alpha}\left(L_{i t}^{\text {comp }}\right)^{1-\alpha}-\xi_{t}^{\text {fixcost }} \phi>0
$$

and $Y_{i t}=0$ otherwise. The stationary TFP shock $z_{t}$ follows an $A R(1)$-process

$$
\log z_{t}=\rho_{1}^{z} \log z_{t-1}+e^{\sigma_{t}^{z}} \nu_{t}^{z}, \nu_{t}^{z} \stackrel{i i d}{\sim} \mathcal{N}(0,1)
$$

The fixed cost of production $\phi$ is set to reduce economic profits to 0 in steady state, thereby ruling out entry or exit (Christiano et al., 2005). $\xi_{t}^{\text {fixcost }}$ is a real supply shock that leads to time-variation in the firms' fixed costs. It follows an $A R(1)$-process

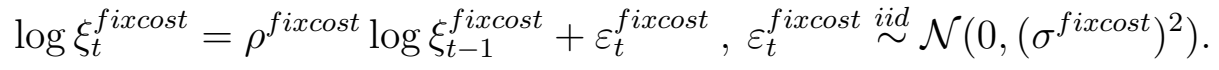

Andreasen (2012) motivates the inclusion of these real supply shocks economically, e.g., by changes in oil prices or maintenance $\operatorname{costs}^{8}$

The composite labor bundle is built from differentiated labor inputs $L_{i t}(j)$ according to a Dixit-Stiglitz aggregator $L_{i t}^{c o m p}=\left(\int_{0}^{1} L_{i t}(j)^{\frac{\eta_{w}-1}{\eta_{w}}} d j\right)^{\frac{\eta_{w}}{\eta_{w}-1}}$.

We assume staggered price setting a la Calvo-Yun. Each period, intermediate firms can re-optimize their prices with probability $\left(1-\theta_{p}\right), 0<\theta_{p}<1$. In between two periods of re-optimization, prices are indexed to the aggregate price index $P_{t}$ according to $P_{i t+1}=$ $\left(\frac{P_{t}}{P_{t-1}}\right)^{\chi_{p}} P_{i t}=\left(\Pi_{t}\right)^{\chi_{p}} P_{i t}$, where $\chi_{p} \in[0,1]$ governs the degree of indexation. Intermediate

\footnotetext{
${ }^{8}$ Using the more commonly used shocks to firms' markups as a means of introducing real supply shocks is not possible in our model. The use of higher order approximations relies on a finite recursive formulation of the equilibrium conditions, which is not available with Calvo pricing and mark-up shocks (see the discussion in Andreasen, 2012).
} 
goods producers maximize their discounted stream of profits subject to the demand from composite goods producers.

There is a competitive final goods firm, which bundles a final good $Y_{t}$ from a continuum of intermediate goods using a Dixit-Stiglitz aggregation technology with substitution elasticity $\eta_{p}$

$$
Y_{t}=\left(\int_{0}^{1} Y_{i t^{\frac{\eta_{p}-1}{\eta_{p}}}}^{\eta^{\frac{\eta_{p}}{\eta_{p}}}}\right)^{\frac{\eta_{p}}{\eta_{p}}}
$$

Expenditure minimization yields the optimal demand for intermediate good $i$ as $Y_{i t}=$ $\left(P_{i t} / P_{t}\right)^{-\eta_{p}} Y_{t} \forall i$.

\subsection{Government Sector}

Following Leeper et al. (2010), we allow government spending and taxes to react to the state of the economy and the government's financial situation, but only with a one period lag. Specifically, the fiscal variables respond to lagged output and to the lagged debt to GDP ratio. Government spending, which may be thought of as entering the utility function additively separable, follows the process

$$
\begin{aligned}
\log \left(G_{t} / G\right)= & \rho_{1}^{g} \log \left(G_{t-1} / G\right)+\rho_{2}^{g} \log \left(G_{t-2} / G\right) \\
& +\phi_{g D} \log \left(\frac{D_{t-1}}{Y_{t-1}} / \frac{D}{Y}\right)+\phi_{g Y} \log \left(Y_{t-1} / Y\right)+e^{\sigma_{t}^{g}} \nu_{t}^{g},
\end{aligned}
$$

where real debt $B_{t} / P_{t}$ is denoted by $D_{t}$, and variables without time indices denote steady state values. The government finances its expenditures by distortionary taxation of labor income at the rate $\tau_{t}^{n}$ and capital and interest income at rate $\tau_{t}^{k}$. We assume $A R(2)$-processes for the tax rates as this has been found to be a good empirical description for the U.S. (McGrattan, 1994; Mertens and Ravn, 2012)

$$
\begin{aligned}
\tau_{t}^{i}= & \left(1-\rho_{1}^{\tau i}-\rho_{2}^{\tau i}\right) \tau^{i}+\rho_{1}^{\tau i} \tau_{t-1}^{i}+\rho_{2}^{\tau i} \tau_{t-2}^{i} \\
& +\phi_{i D} \log \left(\frac{D_{t-1}}{Y_{t-1}} / \frac{D}{Y}\right)+\phi_{i Y} \log \left(Y_{t-1} / Y\right)+e^{\sigma_{t}^{\tau i}} \nu_{t}^{\tau i} \quad \text { for } i=k, n,
\end{aligned}
$$

where $\tau^{n}$ and $\tau^{k}$ are the unconditional means of the labor and capital tax rates, respectively. The government also sets lump-sum transfers $T_{t}$ as a function of the lagged debt to GDP ratio to assure stability of the model:

$$
\frac{T_{t}}{T}=\left(\frac{D_{t-1}}{Y_{t-1}} / \frac{D}{Y}\right)^{\phi_{T d}} .
$$


This assumed structure yields the government budget constraint

$$
G_{t}+T_{t}+\Phi_{t}+R_{t-1} \frac{B_{t-1}}{P_{t}}=\tau_{t}^{n} W_{t} L_{t}^{c o m p}+\tau_{t}^{k}\left(R_{t}^{K} u_{t} K_{t-1}+\Xi_{t}+\left(R_{t-1}-1\right) \frac{B_{t-1}}{P_{t}}\right)+\frac{B_{t}}{P_{t}}
$$

Transfers plus government spending plus depreciation allowances plus repayment of bonds equal tax revenues from taxing labor, capital income, bond income and profits plus proceeds from new bonds.

We close the model by assuming that the central bank follows a Taylor rule that reacts to inflation and output growth.

$$
\frac{R_{t}}{R}=\left(\frac{R_{t-1}}{R}\right)^{\rho_{R}}\left(\left(\frac{\Pi_{t}}{\Pi}\right)^{\phi_{R \pi}}\left(\frac{Y_{t}}{Y_{t-1}}\right)^{\phi_{R y}}\right)^{1-\rho_{R}} \exp \left(m_{t}\right) .
$$

Here, $\rho_{R}$ is a smoothing parameter introduced to capture the empirical evidence of gradual movements in interest rates (e.g. Clarida et al., 2000), $\Pi$ is the target interest rate set by the central bank, and the parameters $\phi_{R y}$ and $\phi_{R \pi}$ capture the responsiveness of the nominal interest rate to deviations of inflation and output growth from their steady state values. We assume that the central bank responds to changes in output rather than its level as this specification conforms better with empirical evidence and avoids the need to define a measure of trend growth that the central bank can observe (see Lubik and Schorfheide, 2007). Finally, $m_{t}$ is a shock to the nominal interest rate that follows an $A R(1)$-process

$$
\log m_{t}=\rho_{1}^{m} \log m_{t-1}+e^{\sigma_{t}^{m}} \nu_{t}^{m}
$$

The definition of equilibrium and the market aggregation are standard and omitted for brevity.

\section{Policy Risk: Time Series Evidence}

In this section, we present empirical evidence on the importance of time-varying volatility in modeling macroeconomic time series. We demonstrate that the data tend to reject the homoscedasticity of macroeconomic driving processes and show that a stochastic volatility (SV) model is able to capture the salient features of the data. Using a particle smoother, we are also able to recover the historical series of uncertainty shocks.

\subsection{Estimation Methodology}

We perform a two-step estimation procedure. Due to the non-linear solution of the model required to capture uncertainty effects and the high-dimensional state space, it is compu- 
tationally infeasible to jointly estimate all model parameters. Hence, we first estimate the exogenous stochastic driving processes of the model featuring time-varying volatility using Sequential Monte Carlo (SMC) methods. In the next section, we feed these processes into the model presented in Section 3 and estimate the parameters of the remaining model equations with a Simulated Method of Moments (SMM) approach.

The model includes 6 exogenous stochastic driving processes with time-varying volatility, i.e., capital and labor tax rates, government spending, a monetary policy shock, total factor productivity, and investment-specific technology. We estimate these processes on quarterly U.S. time series, starting in 1970Q1 and using the longest available sample for each series. Details about the data sources can be found in Online Appendix A. ${ }^{9}$ Because we use a stationary model, we need to extract the deviations of the non-stationary time series from their respective trend. Hence, we apply a one-sided HP-filter to the logarithms of government spending, output, TFP, and investment-specific technology. Using a one-sided, i.e., "causal" filter (Stock and Watson, 1999) assures that the time ordering of the data remains undisturbed and the autoregressive structure is preserved. We allow for AR(1)-processes in TFP (equation (9)) and the monetary policy shocks, ${ }^{10}$ and for an $\mathrm{AR}(2)$-process in investment specific technology (equation (5)), because for the latter the partial autocorrelation indicates the presence of a second root different from zero. The estimated policy rules are given by equations (12)-(13), and (17). Figure A.1 in Online Appendix A shows the time series of the exogenous driving processes on which we estimate our laws of motion. In particular for monetary policy, the presence of time-varying volatility is immediately evident. In Online Appendix C.1, we provide further evidence for the presence of time-varying volatility.

We model the standard deviations $\sigma_{t}^{i}$ as an $\mathrm{AR}(1)$ stochastic volatility process ${ }^{11}$ (see, e.g., Fernández-Villaverde et al., 2011; Shephard, 2008)

$$
\sigma_{t}^{i}=\left(1-\rho^{\sigma_{i}}\right) \sigma^{i}+\rho^{\sigma_{i}} \sigma_{t-1}^{i}+\eta_{i} \varepsilon_{t}^{i}, \quad \varepsilon_{t}^{i} \stackrel{i i d}{\sim} \mathcal{N}(0,1)
$$

where $\sigma^{i}$ is is the unconditional mean of $\sigma_{t}^{i}, i \in\{\tau k, \tau n, g, m, z, z I\}$. The shock to the volatility $\varepsilon_{t}^{i}$ is assumed to be independent of the level shock $\nu_{t}^{i}$.

Due to the nonlinearity embedded in the stochastic volatility setup of the shocks, we cannot simply employ the Kalman filter as in the case of linearity and normally distributed shocks. For this case, Fernández-Villaverde and Rubio-Ramírez (2007) propose to use the Sequential Importance Resampling $(S I R)$ particle filter, a special application of the more

\footnotetext{
${ }^{9}$ The online appendix is available on the authors' websites

${ }^{10}$ Although theory suggests that monetary policy shocks in the Taylor rule should be unpredictable and thus i.i.d., we find a moderate degree of first-order autocorrelation.

${ }^{11}$ For a motivation of the modeling choice, see Online Appendix B.1.
} 
general class of $S M C$ methods, to evaluate the likelihood. ${ }^{12}$

After obtaining the likelihood of the observables given the parameters, we use a Tailored Randomized Block Metropolis-Hastings (TaRB-MH) algorithm (Chib and Ramamurthy, 2010) to maximize the posterior likelihood. The prior distributions of the parameters, which are relatively weak, are given in Table 2 . Note that we do not a priori impose debt stabilizing feedback for every single fiscal instrument, but use a symmetric prior around 0 feedback.

After filtering, it is straightforward to employ the backward-smoothing routine (Godsill et al., 2004) to obtain a historical distribution of the volatilities.

\subsection{Estimation Results}

The estimation results are presented in Table $2 .{ }^{13}$ In general, all parameters are quite precisely estimated as evidenced by the percentiles. All shocks, except for the monetary policy shock, exhibit a high degree of persistence in their levels, with less persistence in their volatilities. Moreover, the estimated processes show considerable evidence of time-varying uncertainty, with $\eta^{i}$ ranging between 0.30 and 0.65. A one-standard deviation uncertainty shock increases the volatility of the respective process by $\left(\exp \left(\eta^{i}\right)-1\right) \times 100$ percent, i.e., such a shock increases the standard deviation of capital taxes, labor taxes, TFP, investment specific technology, monetary policy, and government spending by $48 \%, 86 \%, 37 \%, 36 \%, 36 \%$, and $45 \%$, respectively. ${ }^{14}$

Regarding the feedback rules, our estimates show a relatively strong debt stabilizing feedback from output to taxes and government spending. This contrasts with the direct debt feedback itself. Both labor and capital taxes tend to decrease if debt increases, but the estimates are only marginally significant. Most of the debt stabilization seems to derive from government spending, which considerably falls when debt increases. ${ }^{15}$

The relevance of stochastic volatility in modeling the behavior of the exogenous driving processes can be seen in the smoothed estimates of the historical variances of the shocks in Figure 1. The 1970s were plagued by high shock volatilities, both in technology and policy shocks. Volatilities are at their sample maxima for both tax rates and technology shocks. In contrast, the decade from 1985 to 2000 was characterized by shock volatilities to the technology variables below their unconditional mean. From about 1990 onwards volatilities of

\footnotetext{
${ }^{12}$ Technical details of the algorithms used in this subsection can be found in Appendices B.2-B.4.

${ }^{13}$ Detailed convergence diagnostics are shown in Online Appendix C.2. Online Appendix C.3 shows the results of model misspecification tests applied to the SV model. In general, the model fits the data well and cannot be rejected.

${ }^{14}$ Thus, e.g., a one-standard deviation capital tax risk shock increases the volatility of the capital tax shocks from $\exp (-5.07)=0.63 \%$ to $\exp (-5.07+0.39)=0.93 \%$.

${ }^{15}$ The estimated fiscal rules are consistent with the results found for a slightly different specification in Born et al. (forthcoming).
} 
Table 2: Prior and Posterior Distributions of the Shock Processes

\begin{tabular}{|c|c|c|c|c|c|c|}
\hline \multirow[t]{2}{*}{ Parameter } & \multicolumn{3}{|c|}{ Prior distribution } & \multicolumn{3}{|c|}{ Posterior distribution } \\
\hline & Distribution & Mean & Std. Dev. & Mean & 5 Percent & 95 Percent \\
\hline \multicolumn{7}{|c|}{ Capital Tax Rates } \\
\hline$\rho_{1}$ & Uniform* & 0.00 & 0.577 & 0.743 & 0.705 & 0.783 \\
\hline$\rho_{2}$ & Uniform* & 0.00 & 0.577 & 0.190 & 0.153 & 0.224 \\
\hline$\rho_{\sigma}$ & Beta* & 0.90 & 0.100 & 0.806 & 0.762 & 0.867 \\
\hline$\eta_{\sigma}$ & Gamma & 0.50 & 0.100 & 0.394 & 0.350 & 0.436 \\
\hline $\bar{\sigma}$ & Uniform & -7.00 & 5.333 & -5.073 & -5.351 & -4.820 \\
\hline$\phi_{d}$ & Normal & 0.00 & 1.000 & -0.001 & -0.002 & 0.000 \\
\hline$\phi_{y}$ & Normal & 0.00 & 1.000 & 0.079 & 0.058 & 0.099 \\
\hline \multicolumn{7}{|c|}{ Labor Tax Rates } \\
\hline$\rho_{1}$ & Uniform* & 0.00 & 0.577 & 0.971 & 0.936 & 1.004 \\
\hline$\rho_{2}$ & Uniform* & 0.00 & 0.577 & 0.029 & -0.004 & 0.064 \\
\hline$\rho_{\sigma}$ & Beta* & 0.90 & 0.100 & 0.659 & 0.589 & 0.757 \\
\hline$\eta_{\sigma}$ & Gamma & 0.50 & 0.100 & 0.619 & 0.552 & 0.682 \\
\hline $\bar{\sigma}$ & Uniform & -7.00 & 5.333 & -5.946 & -6.319 & -5.581 \\
\hline$\phi_{d}$ & Normal & 0.00 & 1.000 & -0.000 & -0.000 & 0.000 \\
\hline$\phi_{y}$ & Normal & 0.00 & 1.000 & 0.038 & 0.030 & 0.047 \\
\hline \multicolumn{7}{|c|}{ Investment Specific Technology } \\
\hline$\rho_{1}$ & Uniform* & 0.00 & 0.577 & 1.482 & 1.445 & 1.519 \\
\hline$\rho_{2}$ & Uniform* & 0.00 & 0.577 & -0.548 & -0.576 & -0.520 \\
\hline$\rho_{\sigma}$ & Beta* & 0.90 & 0.100 & 0.842 & 0.805 & 0.890 \\
\hline$\eta_{\sigma}$ & Gamma & 0.50 & 0.100 & 0.304 & 0.275 & 0.333 \\
\hline $\bar{\sigma}$ & Uniform & -7.00 & 5.333 & -6.309 & -6.527 & -6.129 \\
\hline \multicolumn{7}{|c|}{ Government Spending } \\
\hline$\rho_{1}$ & Uniform* & 0.00 & 0.577 & 0.874 & 0.804 & 0.948 \\
\hline$\rho_{2}$ & Uniform* & 0.00 & 0.577 & -0.035 & -0.121 & 0.030 \\
\hline$\rho_{\sigma}$ & Beta* $^{*}$ & 0.90 & 0.100 & 0.655 & 0.551 & 0.848 \\
\hline$\eta_{\sigma}$ & Gamma & 0.50 & 0.100 & 0.309 & 0.228 & 0.396 \\
\hline $\bar{\sigma}$ & Uniform & -7.00 & 5.333 & -4.982 & -5.308 & -4.657 \\
\hline$\phi_{d}$ & Normal & 0.00 & 1.000 & -0.003 & -0.005 & -0.002 \\
\hline$\phi_{y}$ & Normal & 0.00 & 1.000 & -0.000 & -0.017 & 0.016 \\
\hline \multicolumn{7}{|c|}{ Total Factor Productivity } \\
\hline$\rho_{1}$ & Uniform* & 0.00 & 0.577 & 0.814 & 0.769 & 0.858 \\
\hline$\rho_{\sigma}$ & Uniform* & 0.90 & 0.100 & 0.633 & 0.576 & 0.742 \\
\hline$\eta_{\sigma}$ & Beta* & 0.50 & 0.100 & 0.312 & 0.271 & 0.361 \\
\hline $\bar{\sigma}$ & Gamma & -7.00 & 5.333 & -5.233 & -5.437 & -5.030 \\
\hline \multicolumn{7}{|c|}{ Monetary Policy Shock } \\
\hline$\rho_{1}$ & Uniform* & 0.00 & 0.577 & 0.388 & 0.355 & 0.423 \\
\hline$\rho_{\sigma}$ & Uniform* & 0.90 & 0.100 & 0.925 & 0.904 & 0.949 \\
\hline$\eta_{\sigma}$ & Beta* $^{*}$ & 0.50 & 0.100 & 0.374 & 0.344 & 0.405 \\
\hline $\bar{\sigma}$ & Gamma & -7.00 & 5.333 & -5.061 & -5.341 & -4.763 \\
\hline
\end{tabular}

Notes: $\rho$ denotes the autocorrelation coefficient(s) of the level equation, $\rho_{\sigma}$ the one of the volatility equation, $\bar{\sigma}$ is the steady state volatility of the level shocks, $\eta_{\sigma}$ denotes the standard deviation of the volatility shocks, $\phi_{d}$ is the debt feedback coefficient, and $\phi_{y}$ the output feedback coefficient. Beta* indicates that the parameter divided by 0.999 follows a beta distribution. Uniform* indicates that the roots of the autoregressive process are estimated instead of the autoregressive coefficients 5 and follow the specified prior distribution. 
tax and government spending shocks also declined, although the change in volatility is not as pronounced for the latter. For monetary policy shocks, there is clear evidence of a lower shock volatility following the Volcker disinflation from 1979-1983, a trend that continued under Greenspan. In contrast, the early tenure of Volcker experienced a volatility of monetary shocks considerably larger than during the first oil price shock. In the late 2000s the volatility of TFP shocks somewhat increased again. The largest changes in volatility in the 2000s came under George W. Bush who considerably changed the tax law, resulting in a pronounced increase in the volatility of tax rates. At the end of our sample, the Great Recession again results in an increase in policy risk with a rise in the volatility of government spending, tax rates, and monetary policy to comparable levels as after $9 / 11$. For government spending and taxes, this mostly reflects the provisions in the American Recovery and Reinvestment Act that contained $\$ 288$ billion in tax relief to companies and individuals, e.g., in the form of $\$ 116$ billion in payroll tax relief. 


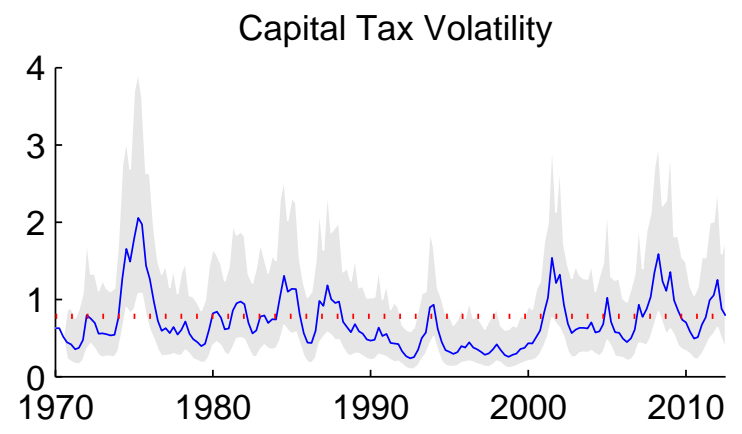

Government Spending Volatility
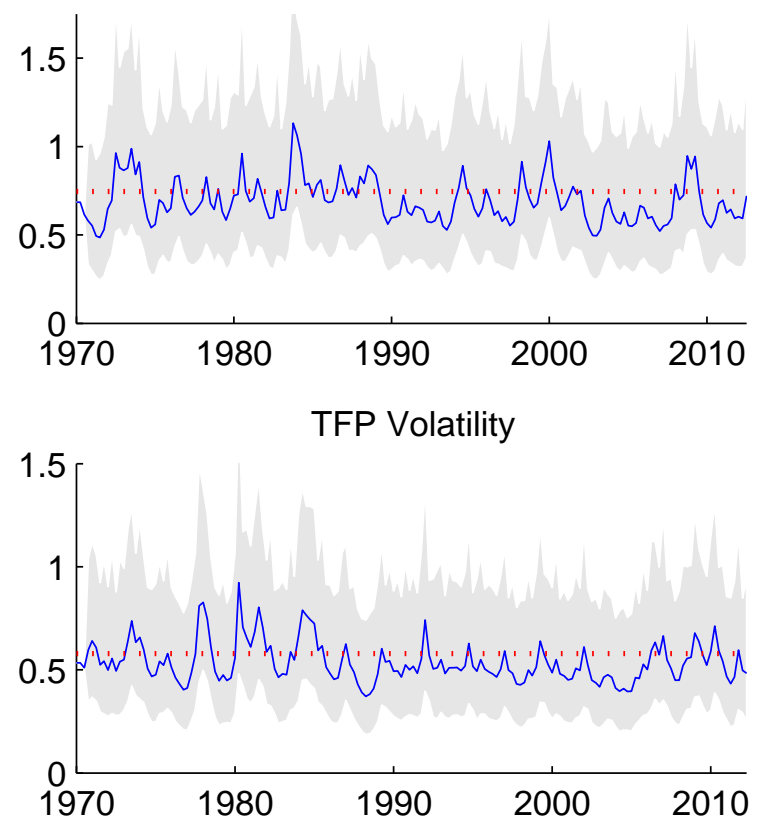

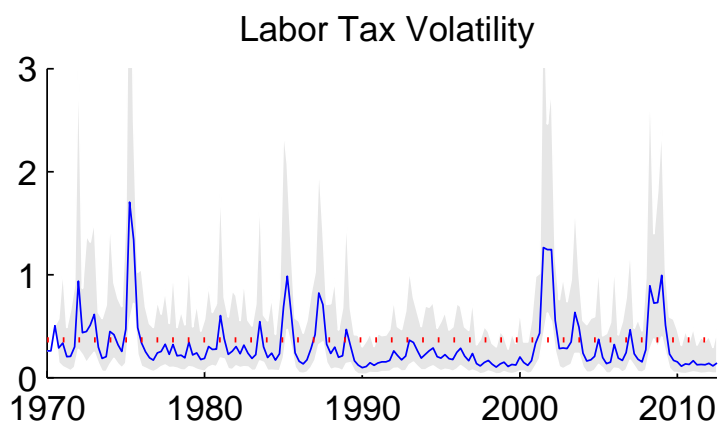

Monetary Policy Shock Volatility

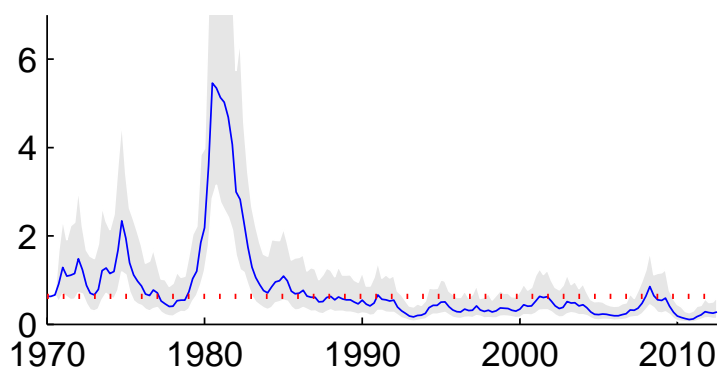

Invest. Spec. Techn. Volatility

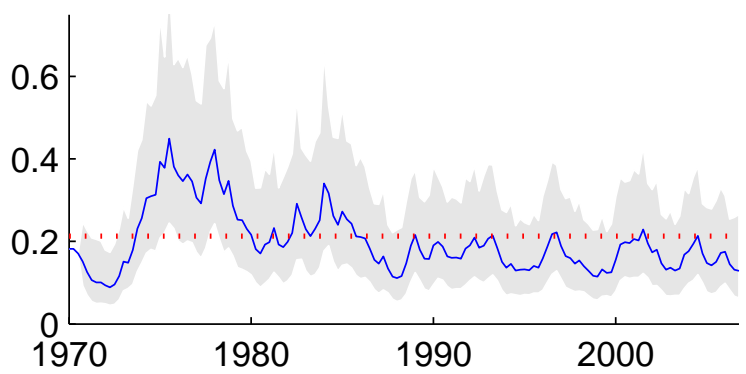

Figure 1: Historical smoothed standard deviations in percent.

Notes: Red dotted line: unconditional mean; shaded area: two standard deviation bands.

\section{$5 \quad$ Fitting the Model to the Data}

Using the parameter estimates of the stochastic driving processes obtained in the previous section, we are now in a position to estimate the deep parameters of the model presented in Section 3.

\subsection{Simulated Method of Moments Estimation}

We use the Simulated Method of Moments (SMM) approach as proposed in Ruge-Murcia (2012). Intuitively, this method minimizes the weighted distance between the empirical moments and the moments resulting from artificial data simulated from the model (details can be found in Online Appendix B.6). 
Table 3: Parameters fixed prior to estimation

\begin{tabular}{cccl}
\hline Parameter & Description & Value & Target/Motivation \\
\hline$\Pi$ & Steady state inflation & 1 & Zero infl. steady state \\
$\beta$ & Discount factor & 0.99 & Standard value \\
$\delta_{0}$ & Steady state depreciation & 0.025 & $10 \%$ annual deprec. \\
$\delta_{1}$ & Capital utilization cost parameter & 0.0351 & $u=1$ \\
$\delta_{\tau}$ & Depreciation rate for tax purposes & 0.05 & Auerbach (1989) \\
$\phi$ & Steady state fixed costs & 0.038 & 0 profits in SS \\
$D / Y$ & Steady state debt share & 1.5 & Avg. debt/ann. GDP: 37.5 \\
$\sigma_{c}$ & Risk aversion coefficient & 2 & Standard value \\
$\sigma_{G}$ & Parameter governing wealth effect & 0.001 & Jaimovich-Rebelo (2009) \\
$\eta_{p}$ & Demand elasticity goods & 10 & $11 \%$ Markup \\
$\eta_{w}$ & Demand elasticity labor & 10 & $11 \%$ Markup \\
$\phi_{T d}$ & Debt feedback & 1 & Assure stability of debt \\
$\tau^{n}$ & Steady state labor tax rate & 0.2264 & Sample mean \\
$\tau^{k}$ & Steady state capital tax rate & 0.3718 & Sample mean \\
$G / Y$ & Government spending share & 0.1989 & Sample mean \\
$\alpha$ & Capital share & 0.319 & Sample mean \\
\hline
\end{tabular}

In order to simulate data, we first need to solve the model non-linearly. Due to the high-dimensional state space of our model, we employ perturbation methods to obtain an approximation of the policy function around the deterministic steady state. Specifically, we need to obtain a third-order approximation, because we are interested in the pure effects of volatility shocks, i.e., when holding the level shocks constant. Loosely speaking, a first-order approximation yields no effects of uncertainty; a second-order approximation yields both a constant effect and an effect mediated through the corresponding level shock. Only in the third-order approximation does time-varying uncertainty play a separate role (for a more detailed explanation, see Online Appendix B.5).

Table 3 presents the values of parameters we fix prior to the estimation. We set gross steady state inflation $\Pi$ to 1 and the discount factor $\beta$ to 0.99 . Regarding the depreciation parameters, $\delta_{0}=0.025$ is chosen to imply a $10 \%$ annual depreciation rate, $\delta_{1}=0.0351$ sets the steady state capital utilization to 1 , and the depreciation rate for tax purposes $\delta_{\tau}$ is set to twice the rate of physical depreciation (Auerbach, 1989). The fixed-cost parameter $\phi=0.038$ implies that firms make zero profit in steady state. Regarding the preference parameters, we set the parameter governing the intertemporal elasticity of substitution $\sigma_{c}$ to 2 and set $\sigma_{G}=0.001$, the value chosen in Jaimovich and Rebelo (2009). ${ }^{16}$ Hence, preferences are close

\footnotetext{
${ }^{16}$ When attempting to estimate this parameter, it hit the lower bound of 0 as in Schmitt-Grohé and Uribe (2012). Hence, we fix the parameter to a small value that still assures a balanced growth path.
} 
to the GHH-specification and imply a small wealth effect on labor supply, which is consistent with evidence from studies focusing on the effects of news (Schmitt-Grohé and Uribe, 2012) and government spending (Monacelli and Perotti, 2008). We set the feedback parameter of debt to transfers $\phi_{T d}=1$ to assure stability of debt. ${ }^{17}$ The elasticity of substitution parameters for differentiated labor services and intermediate goods are set to 10, resulting in a steady state markup of $11 \%$. Thus, we take an intermediate position between the $5 \%$ markup argued for in Altig et al. (2011) and the mean of about 20\% estimated in Justiniano et al. (2011, 2013) and Christiano et al. (2005). The capital share $\alpha$, the steady state tax rates $\tau^{k}$ and $\tau^{n}$, the steady state share of government spending to output, and the steady state share of debt to GDP are set to their respective sample means.

The empirical moments to be matched are the standard deviations and first- and secondorder autocovariances of output, consumption, investment, inflation, the real wage, hours worked, and the nominal interest rate. Moreover, we target the covariance of output with the other variables and the mean of hours worked. ${ }^{18}$ All growing variables are logged and in first differences, while gross inflation, the gross federal funds rate, and hours worked enter in log-levels. The even-numbered columns of Table 5 display the respective sample moments.

\subsection{Parameter Estimates}

The parameter estimates are shown in Table 4. All parameters except for the capital adjustment cost parameter $\kappa$ are precisely estimated as seen in columns 4 and 5 . Consumers have moderate habits in consumption with $\phi_{c}=0.49$, which is at the lower end of the range of values generally found in estimated DSGE models (see, e.g., Christiano et al., 2005; Smets and Wouters, 2007). Capital utilization costs show little convexity with $\delta_{2} / \delta_{1}=0.18$, while capital adjustment is costly as indicated by $\kappa=7.42$, ensuring that investment is not excessively volatile. Prices are estimated to be quite sticky with $\theta_{p}=0.77$, implying that on average a firm optimally resets its price once a year. Actual prices change more often as indicated by a moderate degree of price indexation $\chi_{p}=0.54$. The degree of wage stickiness is low with an average duration of about 2 quarters and an indexation to past wage inflation similar to that for prices. In the Taylor rule, there is a moderate degree of interest smoothing. The reaction coefficients of monetary policy are in line with values found in the literature.

An estimated value of $\sigma_{l}=0.40$ implies a Frisch elasticity of $\sigma_{l}^{-1}=2.5$ in the GHH case, which is a bit higher than the range considered in Ríos-Rull et al. (2012), but close to the

\footnotetext{
${ }^{17}$ Upon trying to estimate this parameter, starting at about a value of 0.9 we encountered numerical stability problems and therefore fixed it at the smallest possible value that reliably assured stability.

${ }^{18}$ Due to the use of third-order perturbation techniques, we thus target the mean of the ergodic distribution and not the deterministic steady state.
} 
Table 4: Parameters estimated by SMM

\begin{tabular}{lcccc}
\hline Parameter & Description & Mean & -1 std.-dev. & +1 std.-dev. \\
\hline$\phi_{c}$ & Consumption habits & 0.4911 & 0.4813 & 0.5008 \\
$\gamma$ & Disutility of labor & 3.4805 & 2.8258 & 4.2869 \\
$\delta_{2} / \delta_{1}$ & Capital utilization costs & 0.1795 & 0.1551 & 0.2077 \\
$\kappa$ & Capital adjustment costs & 7.4235 & 4.5672 & 12.0659 \\
$\theta_{p}$ & Calvo parameter prices & 0.7708 & 0.7669 & 0.7747 \\
$\theta_{w}$ & Calvo parameter wages & 0.3776 & 0.3605 & 0.3949 \\
$\chi_{p}$ & Price indexation & 0.5415 & 0.5196 & 0.5633 \\
$\chi_{w}$ & Wage indexation & 0.5273 & 0.4785 & 0.5755 \\
$\sigma_{l}$ & Frisch elasticity parameter & 0.3957 & 0.3752 & 0.4174 \\
$\rho_{R}$ & Interest smoothing & 0.2036 & 0.1951 & 0.2124 \\
$\phi_{\pi}$ & Taylor rule inflation & 1.9131 & 1.9011 & 1.9255 \\
$\phi_{y}$ & Taylor rule output growth & 0.7832 & 0.7201 & 0.8518 \\
\hline
\end{tabular}

Notes: The confidence bands rely on the asymptotic normality of the estimator as shown in equation (B.18). However, this is only a rough approximation as most parameters, e.g., the Calvo parameters, have bounded support.

average Frisch elasticity derived from macro studies (see the discussions in Chetty et al. (2011) and Reichling and Whalen (2012)). As most estimated macro models (e.g. Smets and Wouters, 2007), our model has trouble explaining why aggregate hours fluctuate by more than would be predicted from micro studies using e.g. tax changes (see e.g. Saez et al., 2012). However, there have been recent studies arguing that micro and macro estimates are indeed compatible, if one considers the interaction of wage rigidities with search and matching frictions (Hall, 2009) or, in micro studies, considers the role of human capital over the life cycle (Keane and Rogerson, 2012).

Finally, the volatilities of preference and fixed cost shocks were estimated to be effectively 0 , making the autocorrelation coefficients poorly identified. We therefore do not include them in Table 4. The estimated unimportance of preference and fixed cost shocks suggests that no additional supply and demand wedges are needed on top of the technology and policy shocks in order to fit the data.

Table 5 shows that the model fits the data well. Output is $90 \%$ as volatile in the simulated model as in the data, while investment is somewhat too volatile. The volatility of consumption is well-matched, while its correlation with output is a bit too low. The volatilities of the real wage, inflation, and the nominal interest rate are on target and their correlation with output is well matched. Only the real wage is somewhat too procyclical. The autocorrelations are also in general well-matched. Only investment exhibits a somewhat too low autocorrelation. As could be expected, the first moment of hours is also well matched at 0.3387 compared to 
Table 5: Simulated and Empirical Moments

\begin{tabular}{|c|c|c|c|c|c|c|c|c|c|c|}
\hline & Model & Data & Model & Data & Model & Data & Model & Data & Model & Data \\
\hline & \multicolumn{2}{|c|}{$\sigma\left(x_{t}\right)$} & \multicolumn{2}{|c|}{$\sigma_{x_{t}} / \sigma_{y_{t}}$} & \multicolumn{2}{|c|}{$\rho\left(x_{t}, y_{t}\right)$} & \multicolumn{2}{|c|}{$\rho\left(x_{t}, x_{t-1}\right)$} & \multicolumn{2}{|c|}{$\rho\left(x_{t}, x_{t-2}\right)$} \\
\hline & \multicolumn{10}{|c|}{ a) Baseline } \\
\hline$\Delta y$ & $0.76 \%$ & $0.85 \%$ & 1.00 & 1.00 & 1.00 & 1.00 & 0.37 & 0.29 & 0.17 & 0.24 \\
\hline$\Delta c$ & $0.48 \%$ & $0.55 \%$ & 0.63 & 0.64 & 0.72 & 0.5 & 0.56 & 0.43 & 0.26 & 0.22 \\
\hline$\Delta i$ & $2.92 \%$ & $2.44 \%$ & 3.84 & 2.86 & 0.91 & 0.69 & 0.27 & 0.62 & 0.10 & 0.46 \\
\hline$\pi$ & $0.61 \%$ & $0.62 \%$ & 0.80 & 0.72 & -0.33 & -0.20 & 0.93 & 0.88 & 0.80 & 0.84 \\
\hline$\Delta w$ & $0.39 \%$ & $0.64 \%$ & 51 & 0 . & 0.38 & 0.0 & 0.29 & 0.03 & 0.03 & 0.03 \\
\hline$r$ & $0.91 \%$ & 0.94 & 1.19 & 1.1 & -0.13 & -0.1 & 0.93 & 0.94 & 0.85 & 0.89 \\
\hline$l$ & $2.69 \%$ & $1.64 \%$ & 3.54 & 1.91 & 0.05 & 0.33 & 0.93 & 0.93 & 0.85 & 0.82 \\
\hline & \multicolumn{10}{|c|}{ b) Volatile Counterfactual } \\
\hline$\Delta y$ & $1.58 \%$ & $0.85 \%$ & 1.00 & 1.00 & 1.00 & 1.00 & 0.44 & 0.29 & 0.27 & 0.24 \\
\hline$\Delta c$ & $0.96 \%$ & $0.55 \%$ & 0.61 & 0.6 & 0.81 & 0.5 & 0.74 & 0.43 & 0.49 & 0.22 \\
\hline$\Delta i$ & $5.79 \%$ & $2.44 \%$ & 3.66 & 2.86 & 0.95 & 0.6 & 0.31 & 0.62 & 0.17 & 0.46 \\
\hline$\pi$ & $2.76 \%$ & $0.62 \%$ & 1.75 & 0.72 & -0.15 & -0.20 & 0.97 & 0.88 & 0.92 & 0.84 \\
\hline$\Delta w$ & $0.24 \%$ & $0.64 \%$ & 0.15 & 0.75 & 0.62 & -0.00 & 0.73 & 0.03 & 0.53 & 0.03 \\
\hline$r$ & $4.46 \%$ & $0.94 \%$ & 2.82 & 1.10 & -0.01 & -0.11 & 0.96 & 0.94 & 0.90 & 0.89 \\
\hline$l$ & $5.90 \%$ & $1.64 \%$ & 3.73 & 1.91 & 0.05 & 0.33 & 0.96 & 0.93 & 0.88 & 0.82 \\
\hline
\end{tabular}

Notes: Time series $x_{t}$ are output $\left(y_{t}\right)$, consumption $\left(c_{t}\right)$, investment $\left(i_{t}\right)$, inflation $\left(\pi_{t}\right)$, the real wage $\left(w_{t}\right)$, the nominal interest rate $\left(R_{t}\right)$, and hours worked $l_{t}$. Lowercase letters denotes variables that are logged. The columns show the standard deviation $\sigma\left(x_{t}\right)$, the relative standard deviation compared to output volatility $\sigma_{x_{t}} / \sigma_{y_{t}}$, the correlation with output $\rho\left(x_{t}, y_{t}\right)$, and the first two autocorrelations $\rho\left(x_{t}, x_{t-1}\right)$ and $\rho\left(x_{t}, x_{t-2}\right)$. Some of the target moments are transformed to correlations for better interpretation. The relative standard deviations with respect to the standard deviation of output are only implicitly targeted through the standard deviations of the respective series. 
0.3385 in the data.

A simple counterfactual experiment demonstrates the importance of accounting for timevarying volatility. We completely shut off time-varying volatility by setting the uncertainty shocks to zero and simulate the model again. Compared to the actual data, such an economy fails to generate sufficient volatility: output, consumption, and investment are only about $54 \%, 58 \%$, and $76 \%$ as volatile as the data, respectively (see Table D.1 in Online Appendix D). These results clearly indicate the importance of time-varying volatility in explaining U.S. macroeconomic time series (see, e.g., Justiniano and Primiceri, 2008; Primiceri, 2005).

\section{Impulse Response Analysis}

We now turn to analyzing the effects of aggregate uncertainty on business cycle fluctuations. First, having estimated the deep parameters of the model, we conduct policy experiments to trace out the effects of uncertainty shocks. We then study the transmission of uncertainty shocks into the economy and analyze the underlying amplification mechanisms in order to find out why the effects of uncertainty are not larger.

\subsection{The Aggregate Effects of Policy Risk}

We first analyze the pure uncertainty effect resulting from time-varying volatility by separating it from the ex-post effect of more extreme shock realizations. We do so by computing impulse response functions (IRFs) to uncertainty shocks while keeping the realizations of the level shocks constant. ${ }^{19}$ As is common in the uncertainty literature, we define an uncertainty shock as a two-standard deviation increase in the respective variable's volatility.

The historical volatility estimates shown in Figure 1 indicate that uncertainty about the future path of economic policy increased for all policy instruments during the Great Recession. We simulate such a situation in the form of a simultaneous two-standard deviation increase in policy risk. ${ }^{20}$ Results are shown in Figure 2.

A simultaneous two-standard deviation policy risk shock (solid lines) leads to a quick decrease in output of $0.045 \%$, before output returns to its initial level after 13 quarters and then overshoots. The decrease in output is driven by both consumption and investment, with investment dropping by more than $0.1 \%$. Thus, initially the capital stock falls and needs to be replenished when the shock subsides, resulting in the typical overshooting visible in

\footnotetext{
${ }^{19}$ For details on the computation of IRFs, see Online Appendix B.7.

${ }^{20}$ The separate IRFs to each single policy risk shock are qualitatively very similar, with capital tax risk inducing the strongest output response (see Figure D.2 in Online Appendix D). Concerning technological uncertainty, the impact of TFP uncertainty is larger than that of investment-specific uncertainty. The IRFs to the corresponding level shocks are shown in Figure D.1. They conform to the conventional wisdom.
} 
Cap. Tax. Vol.

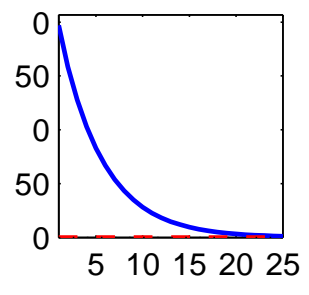

TFP Vol.

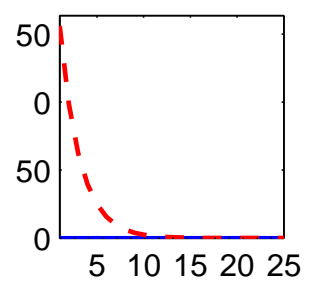

Investment

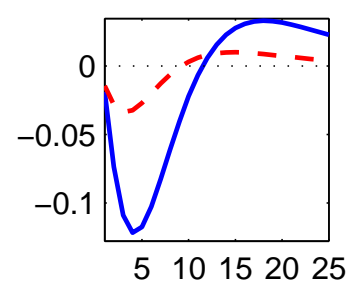

Rental Rate

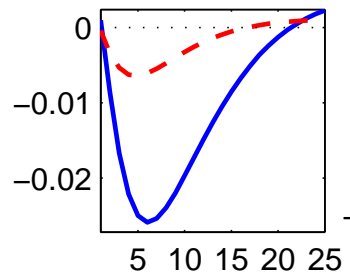

Capital Stock

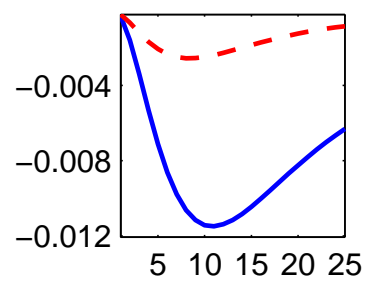

Lab. Tax. Vol.

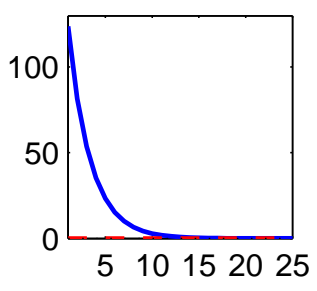

Invest. Spec. Vol.

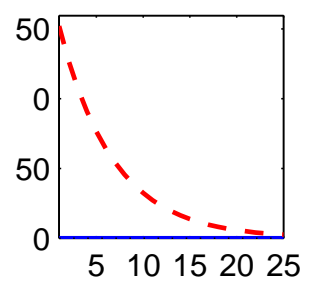

Cap. Serv.

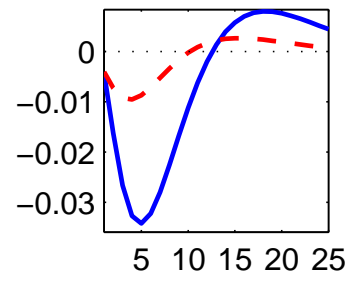

Policy Rate

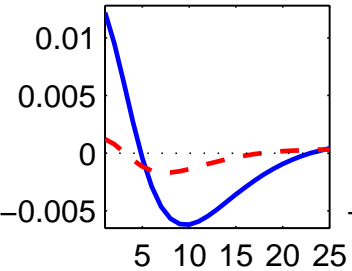

510152025

Marginal Costs

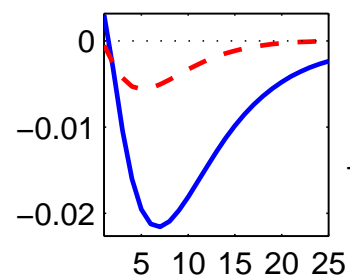

Gov. Spend. Vol.

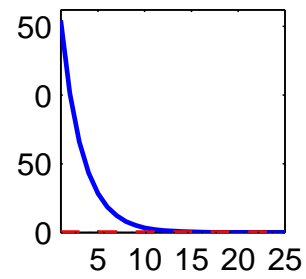

Output

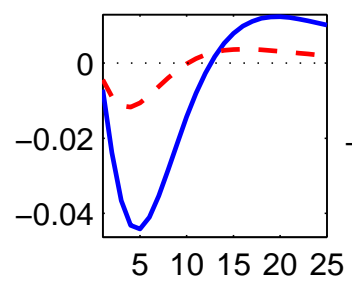

Hours

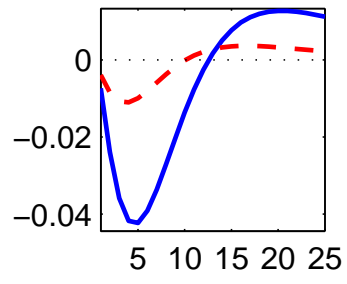

Inflation

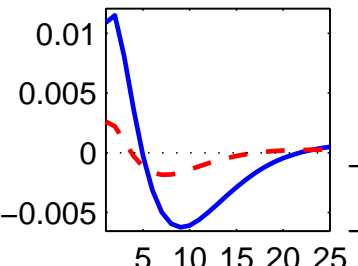

Cap. Util.

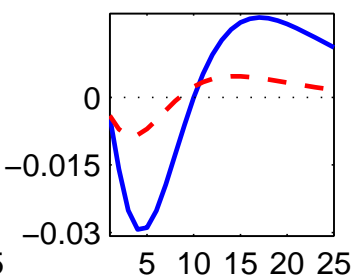

Policy Rate Vol.

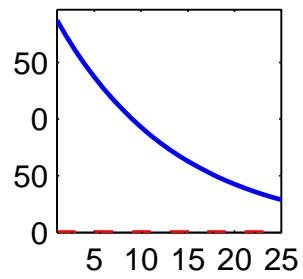

Consumption

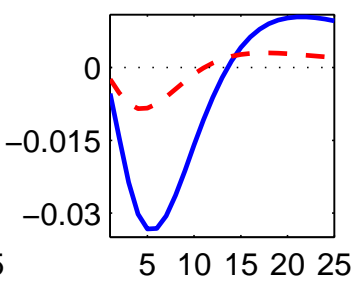

Real Wage

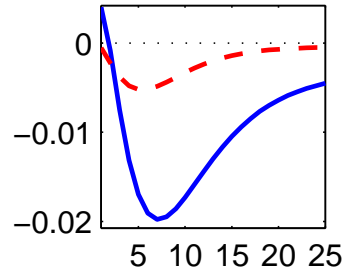

Real Interest Rate

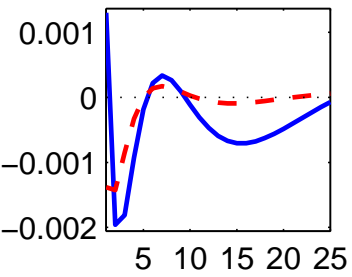

Profits

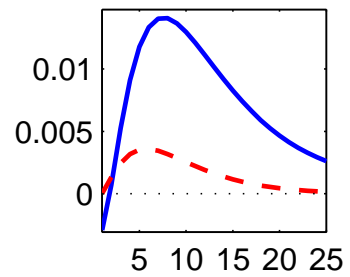

Figure 2: IRFs to a joint two-standard deviation policy risk shock (solid blue line) and to a joint technology risk shock of the same size (dashed red line).

Notes: Level shocks are held constant. All responses are in percent, except for inflation and the interest rates which are in percentage points. The real interest rate is computed as the difference between the policy rate and expected inflation. 
the figure. The drop in output is driven by the interaction of two effects. When uncertainty increases, households desire to consume less and work more due to the precautionary motive. This increase in labor supply ceteris paribus lowers wages and firms' marginal costs and would translate into a drop of prices if the price markup stayed constant. But as prices are sticky and not fully indexed, prices do not fall as much as marginal costs, which leads to an increase in markups (see Basu and Bundick, 2012, on this mechanism). At the same time, firms also face increased uncertainty about future marginal costs and demand conditions. This increased risk has asymmetric effects due to the convexity of the marginal profit curve ("inverse Hartman-Abel effect"). If the future relative price of firm $i$ is set too high, it will sell fewer goods, but at a larger markup over marginal costs. In contrast, if the price is set too low, the firm sells more at a lower or even negative markup, thereby incurring losses. Thus, if uncertainty increases, firms will try to increase their prices to self-insure against being stuck with too low a price. This pricing behavior also tends to increase markups. ${ }^{21}$ In case of an uncertainty shock without subsequent realizations of corresponding level shocks, those two effects together lead to a significant increase in markups as visible by the simultaneous increase in prices and decrease in marginal costs as well as the increase in firm profits $\Xi_{t}$. In an economy that is fundamentally demand driven in the short run, this increase in markups is strongly contractionary. At the same time, through the increase in markups, inflation rises.

Figure 2 also shows the impulse responses to a joint technology risk shock of the type occurring in the middle of the 1970s. The comparison of technology risk (dashed lines) with policy risk (solid lines) shows that while policy risk generates responses that are about four times larger than technological risk, the qualitative mechanism underlying both responses is very similar.

\subsection{Dissecting the Transmission Channels of Uncertainty}

In the previous section we have already seen that the response of the economy to policy risk is mostly driven by the precautionary motive of households and firms combined with the presence of nominal rigidities. This combination leads to significant increases in markups, which due to their depressing effect on demand leads to a drop in output.

A deeper insight into the transmission of uncertainty can be gained by shutting off various features of the model. The consequences for the output response to a policy risk shock when doing this are shown in the panels of Figure 3, where for comparison the solid blue line depicts

\footnotetext{
${ }^{21} \mathrm{~A}$ similar effect is present in the labor market due to the presence of monopolistically competitive unions, but given the estimated parameter values it is considerably less important in quantitative terms. See section 6.2 .
} 

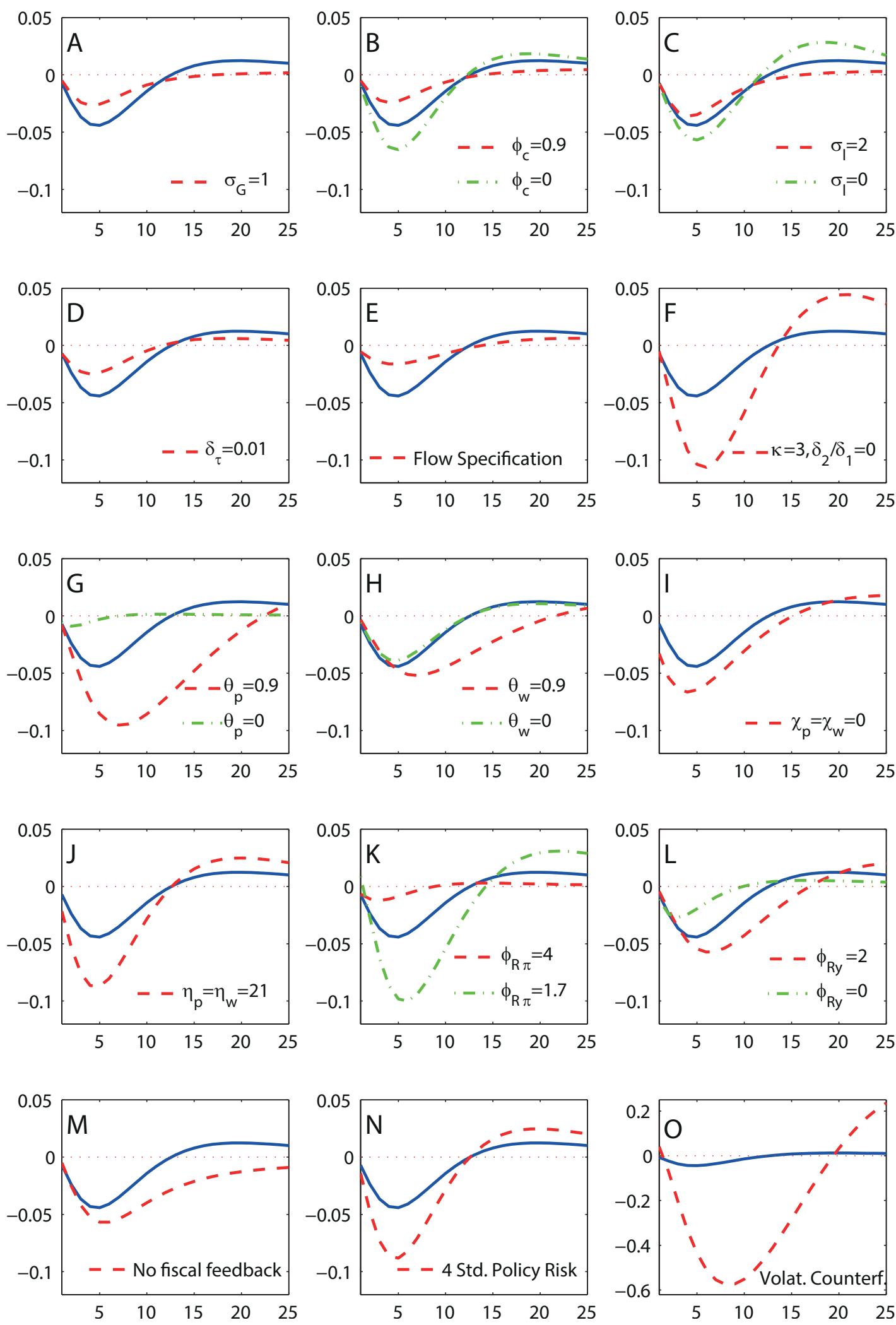

Figure 3: Output IRFs to a joint two-standard deviation policy risk shock. The solid blue line always depicts the output response under the baseline parametrization. Notes: Level shocks are held constant. All responses are in percent. 
the output response under our baseline parametrization. ${ }^{22}$

We start with parameters influencing the behavior of the household and perturb one at a time. First, the low wealth effect on the labor supply implied by the preferences being close to the GHH-form $\left(\sigma_{G} \approx 0\right)$ has a considerable effect on the responses to uncertainty. As shown in Panel A of Figure 3, when setting the preferences to the standard King-Plosser-Rebelo specification $\left(\sigma_{G}=1\right)$, the negative output response is considerably smaller. This decrease in the effects of a policy risk shock is mainly driven by a minuscule response of output to labor tax risk in the KPR case. ${ }^{23}$ Second, increasing the habit persistence parameter $\phi_{c}$ to 0.9 reduces the output response by making consumption react only sluggishly to risk shocks (see Panel B). On the other hand, without habit formation in consumption $\left(\phi_{c}=0\right)$, the precautionary adjustment of consumption is less costly in terms of utility and hence an increase in uncertainty generates a bigger drop in output due to the stronger reaction of consumption demand.

Increasing $\sigma_{l}$ to 2 , and therefore lowering the Frisch elasticity, decreases the fall in output in response to a policy risk shock (see Panel C) through a weaker response of hours worked. Linear labor, i.e., an infinite Frisch elasticity of labor supply in contrast results in a stronger drop of labor and due to this in a bigger output drop. At the same time, it necessitates a smaller equilibrium wage response to clear the labor market.

On the investment side of the model, by fixing the relative price of investment to consumption at $z^{I}=1$, we find that the real option effect embedded in the depreciation allowances via the stochastic resale price of capital hardly plays a role. However, while their role in providing current investment with a tax shield at historical investment prices does not seem to create strong real option effects in our model, this does not mean that depreciation allowances do not play an important role. With their effect on Tobin's marginal $q$ and the capital utilization decision, they have an important amplifying effect on the investment response and hence on output. When lowering $\delta_{\tau}$ from 0.05 to 0.01 , as Panel D shows, investment drops less and the negative output response is cut in half.

Our choice of Hayashi (1982)-type capital adjustment costs (see equation (7)) was motivated in part by the fact that with the flow specification of Christiano et al. (2005), Tobin's marginal $q$ would be independent of the capital stock, which would essentially shut off intertemporal linkages and thereby the option effects (Wu, 2009). To gauge whether this indeed affects the impact of risk shocks in our model, we implement the alternative flow specification of Christiano et al. (2005), keeping the rest of the model and the calibration as in our baseline. The output trough with this alternative adjustment cost specification is only about one third

\footnotetext{
${ }^{22}$ Detailed figures showing the responses of other model variables can be found in Online Appendix D.

${ }^{23}$ See Figure D.3 in Online Appendix D.
} 
of the baseline response (see Panel E), showing that real option effects play a role in the transmission of risk shocks in our model. On the other hand, decreasing the costs of using capital with an intensity higher than normal and of adjusting the capital stock $\left(\kappa\right.$ and $\delta_{2} / \delta_{1}$ in equation 7 ) in the stock specification makes the model more volatile and increases the response of output (see Panel F). This indicates that the first-order effect of lower adjustment costs dominates the reduced second-order real option effect arising from lower costly adjustment. Thus, while stronger nominal rigidities amplify the response to uncertainty shocks, larger real rigidities tend to dampen it.

As shown in the previous section, nominal rigidities are key to understand the model response to a policy risk shock due to their effect on markups. Setting price stickiness to zero $\left(\theta_{p}=0\right)$ and only keeping wage stickiness yields an output response that is only one fourth of the baseline response (see Panel $G$ ). On the other hand, a very high degree of price stickiness $\left(\theta_{p}=0.9\right)$ leads to a trough response of almost $-0.1 \%$. The results are not as pronounced for a change in wage stickiness (see Panel $\mathrm{H}$ ) as its baseline estimate is lower than that of price stickiness. Conforming to our intuition about the importance of nominal rigidities, Panel I shows that shutting off price and wage indexing amplifies the output drop, although the effect is relatively small.

When we increase the steady state demand elasticity to imply a steady state markup of $5 \%$, the value used in Fernández-Villaverde et al. (2012), the trough output drop to a policy risk shock doubles to almost $-0.1 \%$ (Panel $\mathrm{J}$ ). This is due to the higher demand elasticity increasing the convexity of the marginal profit function and hence the "inverse Hartman-Abel effect": for every additional cent the price is set too low, demand increases more and results in selling more goods at a loss. Firms will thus choose larger markups in response to uncertainty shocks to avoid this scenario, thereby increasing the amplification. However, Justiniano et al. (2011, 2013) find a 90\% highest posterior density interval of about 10 to $30 \%$ for the steady state markup, while Christiano et al. (2005) estimate a 95\% confidence interval in the same range. Thus, we think that a markup of $11 \%$ as used in our study already presents an upper bound on the amplification through this channel.

A stronger inflation response of the central bank $\left(\phi_{R \pi}=4\right.$ in Panel $\left.\mathrm{K}\right)$ tends to dampen the effects of uncertainty as the central bank decreases expectations about future inflation and thus the risk of having an undesirably low price relative to other firms that are able to reset prices. With a stronger response to inflation, the central bank comes closer to replicating the flex-price output. This also explains why a stronger output feedback amplifies the output response to uncertainty shocks $\left(\phi_{R y}=2\right.$ in Panel L). In this case, the central bank puts more weight on the output drop than on the increase in inflation, basically accommodating the inflation fears of firms. The importance of the central bank reaction function shows that 
general equilibrium effects may considerably dampen the output effects of uncertainty shocks (see also Bachmann and Bayer, forthcoming).

Shutting off the reaction of government spending and taxes to the state of the economy and the government's financial situation makes the model more volatile and increases the drop in output, as shown in Panel M of Figure 3. The reason is the estimated persistence of the labor tax rate. This persistence is usually dampened by the stabilizing feedback from debt and output. Shutting off this stabilizing effect increases the persistence and thus makes stronger and longer-lasting adjustments necessary.

\subsection{Why are the Effects of Uncertainty not Larger?}

There are two reasons why the output effects of policy risk are not larger, which are essentially two sides of the same coin: the aggregate policy risk shocks are $i$ ) too small and ii) not sufficiently amplified.

The parameter perturbations in Section 6.2 have shown that the model is in principle capable of generating larger business cycle effects of uncertainty. A natural counterfactual experiment therefore is to simultaneously change a number of estimated parameters at the same time to values that yield more "bang for the buck" in response to an uncertainty shock. Specifically, we set $\delta_{2} / \delta_{1}=0$ and $\kappa=3$, allowing for a stronger response of investment, increase wage rigidities to $\theta_{w}=0.75$, and lower the monetary policy response to inflation to $\phi_{R \pi}=1.7$, implying a weaker commitment of the central bank to pursue the flex-price output. This new calibration indeed yields a larger output drop of $-0.6 \%$, more than one order of magnitude larger than in our baseline parametrization. However, looking at the implied moments, this model is much too volatile (see Panel b of Table 5). The reason is that the parameter changes do not only amplify the (second moment) risk shocks, but also the level shocks. Given the estimated parameter values and the resulting amplification, the risk shocks are too small relative to the level shocks.

Our results suggest that for policy risk shocks to matter, we might need an extraordinarily large uncertainty shock. Was such a large shock that exceeded the two standard deviations of our experiments present during the Great Recession? Both the historical smoothed volatilities of the policy variables in our model (see Figure 1) and the Baker et al. (2013)-index of economic policy uncertainty increased by 3 to 4 standard deviations. But even such a large shock is not capable of generating a major drop in output. Panel N shows that a four-standard deviation policy risk shock results in a trough response of slightly less than $-0.1 \%$.

The flipside of this is that given the relative sizes of the level and risk shocks, the propagation of risk shocks is not strong enough compared to that of the level shocks. One way to generate such an asymmetric amplification in the context of a standard New Keynesian 
business cycle model is the use of a larger demand elasticity/smaller steady state markup (e.g., suggested in Fernández-Villaverde et al., 2012), which increases the curvature of the firms' revenue function and thus has a stronger effect on risk than on level shocks. However, as discussed in Section 6.2, we think that a markup of $11 \%$ as used in our study already presents an upper bound on the amplification through this channel. Chugh (2011) has taken a different approach in the context of TFP risk by integrating uncertainty about technology in a financial accelerator model, thereby upgrading uncertainty shocks from a second to a first order shock. However, even in this case uncertainty shocks have only very muted output effects. Thus, future work should focus on identifying potential channels of asymmetric amplification.

One amplification mechanism that could potentially be relevant for the Great Recession is the zero lower bound (ZLB). We showed in the previous section that when the central bank does not counteract nominal rigidities by strongly reacting to inflation and thus replicating the flex-price output after an uncertainty shock, the negative output effects of a policy risk shock increase significantly. This also suggests strong effects when the central bank cannot react strongly to movements in the price level. This conjecture is corroborated by recent work of Basu and Bundick (2012) using a stylized New Keynesian model solved with global solution techniques. In their model, if the central bank is constrained by the zero lower bound, it is unable to replicate the flex-price outcome and hence unable to undo the negative effects of uncertainty shocks. Even after controlling for the "contractionary bias" arising from the interaction of uncertainty and the zero lower bound, i.e., the fact that expected real interest rates increase after an uncertainty shock due to the left truncation of nominal interest rates, being at the zero lower bound doubles the effects of the discount factor uncertainty shock they consider.

Johannsen (2013) explicitly analyzes the effects of fiscal policy uncertainty and shows that the amplification effects of the zero lower bound are also true for policy uncertainty. The reason is the strongly asymmetric response of the economy to fiscal policy. ${ }^{24}$ As shown in, e.g., Christiano et al. (2011b), fiscal multipliers at the zero lower bound may be large. It follows that the downside risk part of increased uncertainty about government spending consists of a very large contraction due to the ZLB continuing to bind and multipliers being very high for the whole left tail of the distribution. In contrast, the upside risk consists of fiscal policy pushing the economy to regions, where the ZLB stops to bind and multipliers will be at a normal level. Thus, the left tail is associated with catastrophic downturns, while the right tail only leads to moderate expansions. Households would like to insure against this downside risk by saving and working more, thereby decreasing inflation and increasing the real interest rate,

\footnotetext{
${ }^{24}$ However, he only considers a stylized Taylor Rule where the central bank only reacts to inflation. As output feedback acts in the opposite direction as shown in Section 6.2, the implications of the zero lower bound for our model are not unambiguous.
} 
given that the nominal rate is stuck at zero. This increase in the real rate, which would not occur if the general equilibrium response of the central bank were operational, considerably increases the contractionary effect of policy risk.

Our results above indicate that while increasing the absolute effect of uncertainty shocks on output, the zero lower bound most probably leaves their relative importance compared to other shocks unaltered, because level shocks experience a similar amplification. Thus, unless we think that policy uncertainty shocks were extraordinarily large compared to other shocks like government spending or wealth shocks during the Great Recession, something we do not see in our data, it seems unlikely that policy uncertainty is the main culprit for the prolonged slump..$^{25}$

At the same time, our results suggest that unconventional monetary policy may have an important effect on the amplification of policy uncertainty shocks at the ZLB. On the one hand, it might be effective in counteracting the negative output effect by undoing some of the effects of nominal rigidities by restoring the Taylor rule feedback. On the other hand, if unconventional monetary policy like "quantitative easing" puts a bigger focus on reactions to output as opposed to inflation and replicating the flex-price output, it might actually increase the negative output effects of uncertainty. Similarly, our results suggest that a credible commitment of the central bank to higher future inflation ("forward guidance") to stimulate output today may actually increase the negative effects of uncertainty shocks through firms and workers today setting higher markups over marginal costs. However, at the same time increasing markups and prices in the short run might be inflationary and lower the real interest rate, exactly what the central bank desires to achieve. This suggests that future research using a formal quantitative model incorporating the ZLB is needed in order to trace out the general equilibrium effects for policy risk shocks at the ZLB.

\section{Conclusion}

This paper analyzes the aggregate effects of policy risk on the business cycle and finds them to be minor. Although the effects of uncertainty about fiscal and monetary policy are four times larger than those of technological uncertainty, a two-standard deviation policy risk shock still only generates a $-0.045 \%$ drop in output.

As shown, the negative effect on output is mainly driven by the price setting behavior of firms constrained by nominal rigidities. Markups rise when uncertainty increases and, given

\footnotetext{
${ }^{25}$ Moreover, as shown by Basu and Bundick (2012), the neoclassical core of New Keynesian models implies that uncertainty effects should be relatively short-lived as prices adjust, which seems to contradict the duration of the Great Recession.
} 
that output is demand-determined in the short run, this results in a drop in output. However, in our estimated model, this drop is relatively small.

The reason for this small effect is that, given the estimated parametrization of the model, the size of the policy risk shocks is too small to cause a more significant drop of output. Even considering the case of the Great Recession, the upper bound of the estimated joint increase in fiscal and monetary uncertainty in our sample, results only in an output drop of $-0.1 \%$. The flipside of this is that the estimated model does not feature a strong enough amplification to transform these uncertainty shocks into large output effects. In principle, a different parametrization like decreasing the inflation feedback in the Taylor rule would allow for a bigger effect of risk shocks. However, such a calibration would imply unrealistically large business cycle fluctuations due to its relatively symmetric amplification of level shocks. This is the reason that the amplification of uncertainty shocks was estimated to be rather low.

Thus, our results also suggest a potential issue for studies using a "proof-of-concept"approach. Such studies typically show that uncertainty may matter by putting one source of uncertainty along one level shock into a model and then designing a transmission mechanism that enables this source to explain the whole business cycle. Our findings indicate that more attention needs to be devoted to what happens if other shocks, both uncertainty and level, are present. Moreover, it does not seem sufficient to consider amplification mechanisms that affect level and uncertainty shocks symmetrically.

\section{References}

Abel, Andrew B. (1983). "Optimal investment under uncertainty". American Economic Review 73 (1), 228-33.

Abel, Andrew B., Avinash K. Dixit, Janice C. Eberly, and Robert S. Pindyck (1996). "Options, the value of capital, and investment". Quarterly Journal of Economics 111 (3), 753-777.

Abramowitz, M. and I. A. Stegun (1965). Handbook of mathematical functions. New York: Dover Publications.

Alexopoulos, Michelle and Jon Cohen (2009). "Uncertain times, uncertain measures". Working Papers. University of Toronto, Department of Economics.

Altig, David, Lawrence Christiano, Martin Eichenbaum, and Jesper Linde (2011). "Firmspecific capital, nominal rigidities and the business cycle". Review of Economic Dynamics $14(2), 225-247$.

Andreasen, Martin M. (2010). "How to maximize the likelihood function for a DSGE model". Computational Economics 35 (2), 127-154.

- (2012). "An estimated DSGE model: explaining variation in nominal term premia, real term premia, and inflation risk premia". European Economic Review 56, 1656-1674.

Andreasen, Martin M., Jesús Fernández-Villaverde, and Juan F. Rubio-Ramírez (2013). "The pruned state-space system for non-linear DSGE models: theory and empirical applications". Tech. rep. mimeo, Aarhus University. 
Arulampalam, M. S., S. Maskell, N. Gordon, and T. Clapp (2002). "A tutorial on particle filters for online nonlinear/non-Gaussian Bayesian tracking". IEEE Transactions on Signal Processing 50, 174-188.

Auerbach, Alan J. (1989). "Tax reform and adjustment costs: the impact on investment and market value". International Economic Review 30 (4), 939-962.

Bachmann, Rüdiger and Christian Bayer (forthcoming). "“Wait-and-See" business cycles?" Journal of Monetary Economics.

Bachmann, Ruediger, Steffen Elstner, and Eric R. Sims (2013). "Uncertainty and economic activity: evidence from business survey data". American Economic Journal: Macroeconomics 5 (2), 217-249.

Baker, Scott, Nicholas Bloom, and Steven Davis (2013). "Measuring economic policy uncertainty". Chicago Booth Research Paper (13-02).

Basu, Susanto and Brent Bundick (2012). "Uncertainty shocks in a model of effective demand". NBER Working Papers 18420.

Basu, Susanto, John G. Fernald, and Miles S. Kimball (2006). "Are technology improvements contractionary?" American Economic Review 96 (5), 1418-1448.

Bekaert, Geert, Marie Hoerova, and Marco Lo Duca (2010). "Risk, uncertainty and monetary policy". NBER Working Papers 16397.

Bernanke, Ben S. (1983). "Irreversibility, uncertainty, and cyclical investment". Quarterly Journal of Economics 98 (1), 85-106.

Binsbergen, Jules H. van, Jesús Fernández-Villaverde, Ralph S.J. Koijen, and Juan RubioRamírez (2012). "The term structure of interest rates in a dsge model with recursive preferences". Journal of Monetary Economics 59 (7), 634-648.

Bloom, Nicholas (2009). "The impact of uncertainty shocks". Econometrica 77 (3), 623-685.

Bloom, Nicholas, Max Floetotto, Nir Jaimovich, Itay Saporta-Eksten, and Stephen J. Terry (2012). "Really uncertain business cycles". NBER Working Papers 18245.

Boehner, John (2010). "Republicans will oppose Democrats' job-killing tax hike on small businesses". Press release. Nov. 19, 2010. URL: http: // boehner . house . gov/news / documentsingle . aspx?DocumentID=215511 (visited on 7/10/2013).

Born, Benjamin, Alexandra Peter, and Johannes Pfeifer (forthcoming). "Fiscal news and macroeconomic volatility". Journal of Economic Dynamics and Control.

Breusch, Trevor S. and Adrian R. Pagan (1979). "A simple test for heteroscedasticity and random coefficient variation". Econometrica 47 (5), 1287-1294.

Cantor, Eric (2010). "Beware of the Obama tax increases". USA Today. Sept. 2, 2010. URL: http://usatoday30.usatoday.com/news/opinion/forum/2010-09-02-cantor01_ST_ N.htm? csp=hf.

Carroll, Christopher D. and Miles S. Kimball (2008). "Precautionary saving and precautionary wealth". The New Palgrave Dictionary of Economics. Ed. by Steven N. Durlauf and Lawrence E. Blume. Basingstoke: Palgrave Macmillan.

Chetty, Raj, Adam Guren, Day Manoli, and Andrea Weber (2011). "Are micro and macro labor supply elasticities consistent? a review of evidence on the intensive and extensive margins". American Economic Review 101 (3), 471-75.

Chib, Siddharta and Srikanth Ramamurthy (2010). "Tailored randomized block MCMC methods with application to DSGE models". Journal of Econometrics 155 (1), 19-38. 
Christiano, Lawrence J., Martin Eichenbaum, and Charles L. Evans (2005). "Nominal rigidities and the dynamic effects of a shock to monetary policy". Journal of Political Economy 113 (1), $1-45$.

Christiano, Lawrence J., Mathias Trabandt, and Karl Walentin (2011a). "Introducing financial frictions and unemployment into a small open economy model". Journal of Economic Dynamics and Control 35 (12), $1999-2041$.

Christiano, Lawrence J., Martin Eichenbaum, and Sergio Rebelo (2011b). "When is the government spending multiplier large?" Journal of Political Economy 119 (1), 78-121.

Chugh, Sanjay K. (2011). "Firm risk and leverage-based business cycles". mimeo. University of Maryland.

Clarida, Richard, Jordi Galí, and Mark Gertler (2000). "Monetary policy rules and macroeconomic stability: evidence and some theory". Quarterly Journal of Economics 115 (1), $147-180$.

Cochrane, John H. (2005). Asset pricing. Revised Edition. Princeton, NJ: Princeton University Press.

Doucet, Arnaud and Adam M. Johansen (2009). "A tutorial on particle filtering and smoothing: fifteen years later". Handbook of Nonlinear Filtering.

Duffie, Darrell and Kenneth J. Singleton (1993). "Simulated moments estimation of markov models of asset prices". Econometrica 61 (4), 929-952.

Eberly, Janice, Sergio Rebelo, and Nicolas Vincent (2008). "Investment and value: a neoclassical benchmark". NBER Working Papers 13866.

Fernald, John (2012). "A quarterly, utilization-adjusted series on total factor productivity". Federal Reserve Bank of San Francisco Working Paper 2012-19.

Fernández-Villaverde, Jesús and Juan Rubio-Ramírez (2007). "Estimating macroeconomic models: a likelihood approach". Review of Economic Studies 7/4 (4), 1059-1087.

(2010). "Macroeconomics and volatility: data, models, and estimation". mimeo. University of Pennsylvania.

Fernández-Villaverde, Jesús, Pablo A. Guerrón-Quintana, and Juan Rubio-Ramírez (2010). "Fortune or virtue: time-variant volatilities versus parameter drifting in U.S. data". NBER Working Papers 15928.

Fernández-Villaverde, Jesús, Pablo A. Guerrón-Quintana, Juan Rubio-Ramírez, and Martín Uribe (2011). "Risk matters: the real effects of volatility shocks". American Economic Review 101 (6), 2530-61.

Fernández-Villaverde, Jesús, Pablo A. Guerrón-Quintana, Keith Kuester, and Juan RubioRamírez (2012). "Fiscal volatility shocks and economic activity". mimeo.

Fields, Gary (2009). "Political uncertainty puts freeze on small businesses". The Wall Street Journal. Oct. 28, 2009. URL: http://online.wsj.com/article/SB125659324579108943. html (visited on $7 / 10 / 2013$ ).

Fisher, Jonas D.M. (2006). "The dynamic effects of neutral and investment specific technology shocks". Journal of Political Economy 114 (3), 413-451.

Geweke, John (1992). "Evaluating the accuracy of sampling-based approaches to the calculation of posterior moments". Bayesian Statistics. Ed. by José. M Bernardo, James O. Berger, A.Philip Dawid, and Adrian F. M. Smith. Vol. 4. Oxford: Clarendon Press, 641-649.

Godsill, Simon J., Arnaud Doucet, and Mike West (2004). "Monte Carlo smoothing for nonlinear time series". Journal of the American Statistical Association 99 (465), 156-168. 
Greenwood, Jeremy, Zvi Hercowitz, and Gregory W. Huffman (1988). "Investment, capacity utilization, and the real business cycle". American Economic Review 78 (3), 402-17.

Greenwood, Jeremy, Zvi Hercowitz, and Per Krusell (1997). "Long-run implications of investment-specific technological change". American Economic Review 87 (3), 342-362.

- (2000). "The role of investment-specific technological change in the business cycle". European Economic Review 44 (1), 91-115.

Hall, Robert E. (2009). "Reconciling cyclical movements in the marginal value of time and the marginal product of labor". Journal of Political Economy 117 (2), 281-323.

Hansen, Nikolaus, Sybille D. Müller, and Petros Koumoutsakos (2003). "Reducing the time complexity of the derandomized evolution strategy with covariance matrix adaptation (CMA-ES)". Evolutionary Computation 11 (1), 1-18.

Hartman, Richard (1972). "The effects of price and cost uncertainty on investment". Journal of Economic Theory 5 (2), 258 -266.

Hayashi, Fumio (1982). "Tobin's marginal q and average q: a neoclassical interpretation". Econometrica 50 (1), 213-24.

Ingersoll, Jonathan E. and Stephen A. Ross (1992). "Waiting to invest: investment and uncertainty". Journal of Business 65 (1), 1-29.

Jaimovich, Nir and Sergio Rebelo (2009). "Can news about the future drive the business cycle?" American Economic Review 99 (4), 1097-1118.

Jarque, Carlos M. and Anil K. Bera (1987). "A test for normality of observations and regression residuals". International Statistical Review / Revue Internationale de Statistique 55 (2), $163-172$.

Johannsen, Benjamin K. (2013). "When are the effects of fiscal policy uncertainty large?" mimeo. Northwestern University.

Jones, John Bailey (2002). "Has fiscal policy helped stabilize the postwar U.S. economy?" Journal of Monetary Economics 49 (4), 709-746.

Justiniano, Alejandro and Giorgio E. Primiceri (2008). "The time-varying volatility of macroeconomic fluctuations". American Economic Review 98 (3), 604-41.

Justiniano, Alejandro, Giorgio E. Primiceri, and Andrea Tambalotti (2011). "Investment shocks and the relative price of investment". Review of Economic Dynamics 14 (1), 101121.

(2013). "Is there a trade-off between inflation and output stabilization?" American Economic Journal: Macroeconomics 5 (2), 1-31.

Keane, Michael and Richard Rogerson (2012). "Micro and macro labor supply elasticities: a reassessment of conventional wisdom". Journal of Economic Literature 50 (2), 464-76.

Kim, Sangjoon, Neil Shephard, and Siddhartha Chib (1998). "Stochastic volatility: likelihood inference and comparison with ARCH models". Review of Economic Studies 65 (3), 36193.

King, Robert G., Charles I. Plosser, and Sergio T. Rebelo (1988). "Production, growth and business cycles: I. the basic neoclassical model". Journal of Monetary Economics 21 (2-3), $195-232$.

Klein, Ezra (2010). "Where was the policy uncertainty in 1993?" Washington Post. Nov. 15, 2010. URL: http://voices . washingtonpost.com/ezra-klein/2010/11/questions_ questions.html (visited on $7 / 10 / 2013$ ). 
Koenker, Roger (1981). "A note on studentizing a test for heteroscedasticity". Journal of Econometrics 17 (1), 107-112.

Kolmogorov, Andrey N. (1933). "Sulla determinazione empirica di una legge di distribuzione". Giornale dell'Istituto Italiano degli Attuari 4 (1933), 83-91.

Leeper, Eric M., Michael Plante, and Nora Traum (2010). "Dynamics of fiscal financing in the United States". Journal of Econometrics 156 (2), 304-321.

Lubik, Thomas A. and Frank Schorfheide (2007). "Do central banks respond to exchange rate movements? a structural investigation". Journal of Monetary Economics 54 (4), $1069-1087$.

McGrattan, Ellen R. (1994). "The macroeconomic effects of distortionary taxation". Journal of Monetary Economics 33 (3), 573-601.

Mendoza, Enrique G., Assaf Razin, and Linda L. Tesar (1994). "Effective tax rates in macroeconomics: cross-country estimates of tax rates on factor incomes and consumption". Journal of Monetary Economics 34 (3), 297-323.

Mertens, Karel and Morten O. Ravn (2012). "Empirical evidence on the aggregate effects of anticipated and unanticipated US tax policy shocks". American Economic Journal: Economic Policy \& (2), 145-81.

Monacelli, Tommaso and Roberto Perotti (2008). "Fiscal policy, wealth effects, and markups". NBER Working Papers 14584.

Pfeifer, Johannes, Benjamin Born, and Gernot Müller (2012). "Terms of trade uncertainty and business cycle fluctuations". mimeo.

Primiceri, Giorgio E. (2005). "Time varying structural vector autoregressions and monetary policy". Review of Economic Studies 72 (3), 821-852.

Reichling, Felix and Charles Whalen (2012). "Review of estimates of the frisch elasticity of labor supply". Working Paper 2012-13. Congressional Budget Office.

Ríos-Rull, José-Víctor, Frank Schorfheide, Cristina Fuentes-Albero, Maxym Kryshko, and Raül Santaeulàlia-Llopis (2012). "Methods versus substance: measuring the effects of technology shocks". Journal of Monetary Economics 59 (8), 826 -846.

Rosenblatt, Murray (1952). "Remarks on a multivariate transformation". Annals of Mathematical Statistics 23 (3), 470-472.

Ruge-Murcia, Francisco J. (2010). "Estimating nonlinear DSGE models by the simulated method of moments". CIREQ Working Paper Series 19-2010.

_ (2012). "Estimating nonlinear DSGE models by the simulated method of moments: with an application to business cycles". Journal of Economic Dynamics and Control 36 (6), 914-938.

Saez, Emmanuel, Joel Slemrod, and Seth H. Giertz (2012). "The elasticity of taxable income with respect to marginal tax rates: a critical review". Journal of Economic Literature 50 (1), 3-50.

Schmitt-Grohé, Stephanie and Martín Uribe (2004). "Solving dynamic general equilibrium models using a second-order approximation to the policy function". Journal of Economic Dynamics and Control 28 (4), 755-775.

_ (2006). "Optimal fiscal and monetary policy in a medium-scale macroeconomic model". NBER Macroeconomics Annual 2005, Volume 20, 383-462.

- (2011). "Business cycles with a common trend in neutral and investment-specific productivity". Review of Economic Dynamics 14 (1), 122-135. 
Schmitt-Grohé, Stephanie and Martín Uribe (2012). "What's news in business cycles". Econometrica 80 (6), 2733-2764.

Shapiro, Samuel S. and Martin B. Wilk (1965). "An analysis of variance test for normality (complete samples)". Biometrika 52 (3/4), 591-611.

Shephard, Neil (2008). "Stochastic volatility models". The New Palgrave Dictionary of Economics. Ed. by Steven N. Durlauf and Lawrence E. Blume. Basingstoke: Palgrave Macmillan.

Smets, Frank and Rafael Wouters (2007). "Shocks and frictions in US business cycles: a Bayesian DSGE approach". American Economic Review 97 (3), 586-606.

Smirnov, Nikolai (1948). "Table for estimating the goodness of fit of empirical distributions". Annals of Mathematical Statistics 19 (2), 279-281.

Stock, James H. and Mark W. Watson (1999). "Forecasting inflation". Journal of Monetary Economics 44 (2), 293-335.

White, Halbert (1980). "A heteroskedasticity-consistent covariance matrix estimator and a direct test for heteroskedasticity". Econometrica 48 (4), 817-838.

Wooldridge, Jeffrey M. (1990). "A unified approach to robust, regression-based specification tests". Econometric Theory 6 (1), 17-43.

Wu, Guiying (2009). "Uncertainty, investment and capital accumulation: a structural econometric approach". PhD thesis. Oxford University.

Yang, Shu-Chun Susan (2005). "Quantifying tax effects under policy foresight". Journal of Monetary Economics 52 (8), 1557-1568. 